NASA/TM-1999-206590

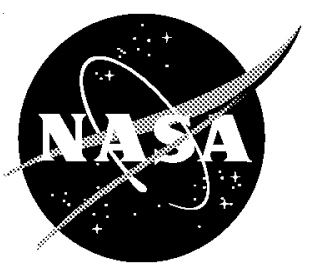

\title{
Propellant Feed System Leak Detection- Lessons Learned From the Linear Aerospike SR-71 Experiment (LASRE)
}

Neal Hass, Masashi Mizukami, Bradford A. Neal, Clinton St. John NASA Dryden Flight Research Center

Edwards, California

Robert J. Beil

NASA Kennedy Space Center

Kennedy Space Center, Florida

Timothy P. Griffin

Dynacs Engineering Co., Inc.

Kennedy Space Center, Florida 


\section{The NASA STI Program Office...in Profile}

Since its founding, NASA has been dedicated to the advancement of aeronautics and space science. The NASA Scientific and Technical Information (STI) Program Office plays a key part in helping NASA maintain this important role.

The NASA STI Program Office is operated by Langley Research Center, the lead center for NASA's scientific and technical information. The NASA STI Program Office provides access to the NASA STI Database, the largest collection of aeronautical and space science STI in the world. The Program Office is also NASA's institutional mechanism for disseminating the results of its research and development activities. These results are published by NASA in the NASA STI Report Series, which includes the following report types:

- TECHNICAL PUBLICATION. Reports of completed research or a major significant phase of research that present the results of NASA programs and include extensive data or theoretical analysis. Includes compilations of significant scientific and technical data and information deemed to be of continuing reference value. NASA's counterpart of peer-reviewed formal professional papers but has less stringent limitations on manuscript length and extent of graphic presentations.

- TECHNICAL MEMORANDUM. Scientific and technical findings that are preliminary or of specialized interest, e.g., quick release reports, working papers, and bibliographies that contain minimal annotation. Does not contain extensive analysis.

- CONTRACTOR REPORT. Scientific and technical findings by NASA-sponsored contractors and grantees.
- CONFERENCE PUBLICATION.

Collected papers from scientific and technical conferences, symposia, seminars, or other meetings sponsored or cosponsored by NASA.

- SPECIAL PUBLICATION. Scientific, technical, or historical information from NASA programs, projects, and mission, often concerned with subjects having substantial public interest.

- TECHNICAL TRANSLATION. Englishlanguage translations of foreign scientific and technical material pertinent to NASA's mission.

Specialized services that complement the STI Program Office's diverse offerings include creating custom thesauri, building customized databases, organizing and publishing research results...even providing videos.

For more information about the NASA STI Program Office, see the following:

- Access the NASA STI Program Home Page at http://www.sti.nasa.gov

- E-mail your question via the Internet to help@sti.nasa.gov

- Fax your question to the NASA Access Help Desk at (301) 621-0134

- Telephone the NASA Access Help Desk at (301) 621-0390

- Write to:

NASA Access Help Desk

NASA Center for AeroSpace Information 7121 Standard Drive

Hanover, MD 21076-1320 


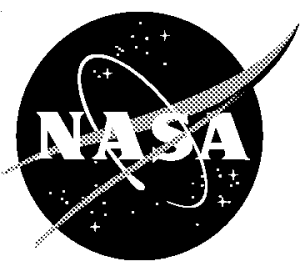

\section{Propellant Feed System Leak Detection- Lessons Learned From the Linear Aerospike SR-71 Experiment (LASRE)}

Neal Hass, Masashi Mizukami, Bradford A. Neal, Clinton St. John NASA Dryden Flight Research Center

Edwards, California

Robert J. Beil

NASA Kennedy Space Center

Kennedy Space Center, Florida

Timothy P. Griffin

Dynacs Engineering Co., Inc.

Kennedy Space Center, Florida

National Aeronautics and

Space Administration

Dryden Flight Research Center

Edwards, California 93523-0273 


\section{NOTICE}

Use of trade names or names of manufacturers in this document does not constitute an official endorsement of such products or manufacturers, either expressed or implied, by the National Aeronautics and Space Administration.

Available from the following:

NASA Center for AeroSpace Information (CASI)

7121 Standard Drive

Hanover, MD 21076-1320

(301) 621-0390
National Technical Information Service (NTIS) 5285 Port Royal Road Springfield, VA 22161-2171 (703) $487-4650$ 


\title{
PROPELLANT FEED SYSTEM LEAK DETECTION-LESSONS LEARNED FROM THE LINEAR AEROSPIKE SR-71 EXPERIMENT (LASRE)
}

\author{
Neal Hass, ${ }^{*}$ Masashi Mizukami, ${ }^{\dagger}$ Bradford A. Neal, ${ }^{\dagger}$ Clinton St. John ${ }^{\S}$ \\ NASA Dryden Flight Research Center \\ Edwards, California \\ Robert J. Beil ${ }^{9}$ \\ NASA Kennedy Space Center \\ Kennedy Space Center, Florida \\ Timothy P. Griffin ${ }^{\#}$ \\ Dynacs Engineering Co., Inc. \\ Kennedy Space Center, Florida
}

\begin{abstract}
$\underline{\text { Abstract }}$
This paper presents pertinent results and assessment of propellant feed system leak detection as applied to the Linear Aerospike SR-71 Experiment (LASRE) program flown at the NASA Dryden Flight Research Center, Edwards, California. The LASRE was a flight test of an aerospike rocket engine using liquid oxygen and highpressure gaseous hydrogen as propellants. The flight safety of the crew and the experiment demanded proven technologies and techniques that could detect leaks and assess the integrity of hazardous propellant feed systems. Point source detection and systematic detection were used. Point source detection was adequate for catching gross leakage from components of the propellant feed systems, but insufficient for clearing LASRE to levels of acceptability. Systematic detection, which used high-resolution instrumentation to evaluate the health of the system within a closed volume, provided a better means for assessing leak hazards. Oxygen sensors detected a leak rate of approximately 0.04 cubic inches per second of liquid oxygen. Pressure sensor data revealed speculated cryogenic boiloff

\footnotetext{
*Aerospace Propulsion Engineer, Member AIAA

$\uparrow$ Aerospace Propulsion Engineer, Member AIAA

†Operations Engineer

§NASA Co-op Student, Purdue University, Student member AIAA

TSenior Engineer

\#Space Shuttle Main Propulsion System Lead Engineer

Copyright (C) 1999 by the American Institute of Aeronautics and
} Astronautics, Inc. No copyright is asserted in the United States under Title 17, U.S. Code. The U.S. Government has a royalty-free license to exercise all rights under the copyright claimed herein for Governmen tal purposes. All other rights are reserved by the copyright owner.
\end{abstract}

through the fittings of the oxygen system, but location of the source(s) was indeterminable. Ultimately, LASRE was canceled because leak detection techniques were unable to verify that oxygen levels could be maintained below flammability limits.

\section{Nomenclature}

Cda theoretical orifice size

$\mathrm{GH}_{2} \quad$ gaseous hydrogen

$\mathrm{GHe} \quad$ gaseous helium

$\mathrm{GN}_{2} \quad$ gaseous nitrogen

$\mathrm{GO}_{2} \quad$ gaseous oxygen

HST Helium Signature Test

$\mathrm{kPa} \quad$ kiloPascals

KSC NASA Kennedy Space Center, Florida

LASRE Linear Aerospike SR-71 Experiment

lbm pounds mass

$\mathrm{LN}_{2} \quad$ liquid nitrogen

$\mathrm{LO}_{2} \quad$ liquid oxygen

LOXMAIN electrical signal name for valve command

MPS Space Shuttle main propulsion system

mdot mass flow

$\mathrm{N}_{2} \quad$ nitrogen

$\mathrm{O}_{2} \quad$ oxygen

$\mathrm{P} \quad$ pressure 


$\begin{array}{ll}\text { Pamb } & \text { ambient pressure } \\ \text { PODPRES } & \text { electrical signal name for pod pressure } \\ \text { ppm } & \text { parts per million } \\ \text { PRECHILL } & \text { electrical signal name for valve command } \\ \text { psi } & \text { pounds per square inch } \\ \text { psia } & \text { pounds per square inch, absolute } \\ \text { Q } & \text { volumetric flow rate } \\ \mathrm{R} & \text { specific gas constant } \\ { }^{\circ} \mathrm{R} & \text { degrees Rankine } \\ \text { Re } & \text { Reynolds number } \\ \text { scim } & \text { standard cubic inches per minute } \\ \text { slpm } & \text { standard liters per minute } \\ \text { T } & \text { temperature, }{ }^{\circ} \mathrm{R} \\ \text { WSTF } & \text { NASA White Sands Test Facility, New } \\ & \text { Mexico } \\ 0 \text { (zero) } & \text { as a subscript denotes initial conditions } \\ \Delta m_{H_{2}} & \text { change in mass of hydrogen } \\ \rho \text { (rho) } & \text { density } \\ & \quad \underline{\text { Introduction }}\end{array}$

The Linear Aerospike SR-71 Experiment (LASRE) was a semi-span 20-percent scale model of the Lockheed Martin X-33 vehicle with an integrated linear aerospike rocket engine fed by liquid oxygen and gaseous hydrogen. The model was mounted to the upper fuselage of the SR-71 aircraft and flight tested with the intention of obtaining data on the pressure compensation performance of the aerospike engine. The program evolved as a partner flight test experiment that directly supported the Lockheed Martin X-33 technology demonstrator, a NASA "Access to Space" program. It was the task of NASA Dryden Flight Research Center to perform the flight tests of the LASRE, and do so in the safest manner possible. Coupling the hazards of this propellant feed system with a piloted flight test vehicle posed a challenging and interesting safety problem. Important issues included early detection of and quantification of the leak rate from high-pressure gaseous hydrogen and liquid oxygen feed lines in a closed, nitrogen purged environment. This hazardous combination required significant validation for confidence in the integrity of the design and operation of the systems. It was not without some risks, and those risks had to be clearly defined by applying practical techniques and tools that would gather data and assess the leak rate of each system. Unfortunately for LASRE, the systematic leak detection systems indicated an unacceptable leak rate of liquid oxygen into the pod environment. The leak source(s) could not be found using what little instrumentation was available and techniques available for detection. These results had a major influence on the decision to discontinue the project. A discussion follows of those leak detection techniques and tools, some of the data, and an analysis of results.

A great deal of experimental research has already been conducted upon the flammability of hydrogen and oxygen mixture ratios. This research demonstrated that the limits for non-flammability of an oxygen and hydrogen mixture is an oxygen volume fraction $\leq 4$ percent and a hydrogen volume fraction $\leq 4$ percent $^{1,2}$ These limits are suggested as the rule of thumb for mission safety for any operations using a combination of these gas components.

Investigations into reduced-pressures flammabilitylimit testing with oxygen and hydrogen mixtures have been conducted as well. Figure $1^{3}$ shows results compiled by NASA White Sands Test Facility (WSTF) on the flammability of reduced-pressure hydrogenoxygen-nitrogen mixtures. Regions to the left and below the isobars are non-flammable at that pressure. Figure $2^{4}$ shows similar results of Benz's work on volume sensitivity and reduced pressures to flammability limits. The results from both of these research efforts indicate that increases in altitude cause little, if any, favorable relief in the flammability limits of hydrogen and oxygen mixtures until altitudes in excess of 80,000 feet $(0.4 \mathrm{psia} / 2.8 \mathrm{kPa}$ pressure altitude) are achieved. Even then, low leak rates from the propellant feed systems might provide enough volume fraction and pressure, if contained, to create a hazardous mixture. Mixed concentrations above these flammability limits are clearly defined as hazardous and require extremely low ignition energy to initiate combustion. In some instances these conditions have led to detonation. The LASRE operational limits of oxygen and fuel concentrations follow the purge discussion in the Experiment System Description section.

Ballistic profiles flown by most launch vehicles shorten the exposure to hazards of flammability with hydrogen and oxygen concentrations by getting very quickly above the pressure altitude where flammability issues exist. Aerospace vehicles designed to operate over flight profile requirements similar to those of conventional commercial aircraft and using hydrogen and oxygen mixtures for fuel, must address flammability as a safety- 
of-flight issue any time they are within the earth's atmosphere. To meet the safety requirements of programs like LASRE, a higher priority is set on leak detection and health assessment capabilities for propellant feed systems than what has been acceptable in the past.

It is the purpose of this paper to provide an assessment of particular leak detection methods and techniques for high-pressure gaseous hydrogen and liquid oxygen propellant feed systems based upon lessons learned from LASRE. In addition, the paper provides suggestions for needed future research and new insight into leak detection strategies, methods, and technologies. One goal of this work is to provide information that will be useful for improving the success of leak detection and assessment for current and future research programs employing hazardous propellant feed systems for aerospace vehicles.

A special thanks is extended to the personnel at Kennedy Space Center and White Sands Missile Range that supported the LASRE program. The insight, experience, and wisdom from these personnel was a welcome addition to the team and they provided a significant contribution to the effort.

Use of trade names or names of manufacturers in this document does not constitute an official endorsement of such products or manufacturers, either expressed or implied, by the National Aeronautics and Space Administration.

\section{Experiment System Description}

The LASRE was a propulsion flight research experiment that intended to obtain hot plume performance data at reduced pressures and multiple Mach numbers for validation and calibration of design predictions. ${ }^{5}$ The linear aerospike rocket engine is significantly different than the conventional bell nozzle design, in the respect that the aerodynamic flow over the vehicle alters with altitude changes resulting in a nozzle that compensates with altitude. Theory and ground testing suggests that the aerospike engine operates with greater efficiency over operating altitudes when compared to the conventional single design point bell nozzle. Data collected by the LASRE flight testing was to be used to support computational fluid dynamics models used for development of the engine and its integration with the X-33 lifting body design. The feed systems designed for LASRE do not reflect those to be employed by the X-33 program.
The LASRE was, in essence, a unique, flightworthy, self-contained, rocket engine test stand. The system was composed of a 20-percent scale, semi-span lifting body model of the Lockheed Martin X-33 attached to the upper fuselage of the SR-71 aircraft. A photograph of the LASRE is shown in figure 3. A simplified schematic of the propellant feed systems internal to the LASRE is shown in figure 4 . As can be seen from the schematic, the flight test hardware is comprised of several parts identified as the "canoe," the "kayak," the "reflection plane," and the "model." The system, as a whole, was referred to as the "pod."

The canoe is a long and sleek fairing design that directly mounts to the SR-71 upper fuselage and is the base of the flight test structure. Contained within this canoe are five gaseous hydrogen $\left(\mathrm{GH}_{2}\right)$ tanks capable of storing up to $27 \mathrm{lbm}$ at $6000 \mathrm{psi}$, two cooling water tanks, and three 10,000 psi helium $(\mathrm{He})$ pressurization tanks.

The kayak is a structure above the canoe that sets the angle of incidence for the model. Atop the kayak is a reflection plane that acts to isolate the flow-field effects between the model and the SR-71 aircraft and pose as the plane of symmetry.

The model is mounted to the top of the reflection plane. Contained within the model are the liquid oxygen $\left(\mathrm{LO}_{2}\right)$ tanks capable of storing $335 \mathrm{lbm}$ and two additional 10,000 psi helium storage tanks used for pressurization. Integrated vertically across the base of the model are eight linear, aerospike thruster segments, arranged four by two running spanwise.

A hollow structure known as the "sewer pipe" extends between the canoe and model (fig. 5). This structure is open-ended and facilitates the instrumentation leads, hydrogen feed lines, cooling water lines to the engine, and allows for purge to flow freely between the model and the canoe. The sewer pipe also carries the loads to be measured by the force balance.

The fuel used by LASRE was gaseous hydrogen $\left(\mathrm{GH}_{2}\right)$. The gaseous hydrogen propellant system operated as a blowdown type of feed system employing a regulator and flow control valve. Once testing was completed, helium purged the feed system and pressurized the tanks to an inert state.

The oxidizer used was liquid oxygen $\left(\mathrm{LO}_{2}\right)$. The liquid oxygen propellant was a pressure-fed system using the onboard helium to provide positive pressure in the oxygen tanks. Upon completion of a test, the remaining 
liquid oxygen was forced overboard and the lines purged by the onboard helium supply.

To mitigate some of the hazards associated with these types of propellant feed systems, the volumes within the canoe and model were purged with nitrogen. The nitrogen was supplied from two liquid nitrogen Dewar flasks that were stored within the SR-71 aircraft. Each Dewar flask has a capacity of $1.76 \mathrm{ft}^{3}$.

All of the systems employed within the pod were heavily instrumented to obtain status information. All tanks and significant stages in the feed lines were instrumented with pressure and temperature instruments. Flight safety instrumentation included firedetection thermocouples and oxygen-detection sensors.

A simplified schematic showing the approximate location of each of the twelve oxygen sensors is shown in figure 5. The oxygen instruments were electrolytictype sensors originally intended for automotive applications. The sensors were temperature controlled to $115^{\circ} \mathrm{F}$ with a heater wrap to reduce any drifting that would have resulted from the extreme temperature changes over the flight profile. The instruments had an accuracy specification of \pm 1 percent volume fraction of oxygen measured. After thorough calibration the oxygen sensors demonstrated an uncertainty that was much better than the advertised accuracy, even over an altitude range from sea level up to $60,000 \mathrm{ft}$ (see figure 6). ${ }^{6}$

There were pressure transducers at two locations within the pod. These instruments monitored the inside-tooutside pressure differential. This monitoring was to ensure that the surface panel stress limits were not exceeded as a result of the pressure differential created by the purge. These ambient pressure transducers were also used as a monitor for over-pressurization resulting from plumbing bursts or leaks, and deflagration or detonation of combustibles. For the purposes of this discussion, the focus is on the unit monitoring the model volume.

\section{$\underline{\text { Leak Detection Techniques and Results }}$}

A considerable amount of effort has been put forth to develop techniques, tools, and strategies for identifying leaks in propellant feed systems. The fundamental principles and techniques behind leak detection of propellant feed systems that were developed in the dawn of the space age are still in use today. Improvements in instrumentation resolution provide better accuracy in assessing hazards and increased bandwidth capabilities allow more information to be attained nearly instantaneously for clarification of the hazard.

The methods and techniques for detection were broken down into two classifications for this paper. The first classification is the point source leak detection which encompasses detection and evaluation of leakage at individual sources. The second classification, systematic leak detection, detects and evaluates the overall leakage from the system.

\section{Point Source Detection Tools and Techniques}

Point source methods for leak detection of gaseous and cryogenic systems include: visual inspection, bubble solution, ultrasonic leak detectors, thermal conductivity sensor, joint bagging, and mass spectrometers. In addition to these tools, inspection of cryogenic lines and fittings with the naked eye is always a useful tool. When cryogenics are flowing drips and vapor trails can often be seen. All of these techniques and tools require direct access to each of the fittings and components of the propellant feed system in order to evaluate the integrity at each junction.

For LASRE, the leak-rate specification for each fitting was to be no greater than the equivalent of bubble tight (a bubble formation within one minute of time). As a result of the way the LASRE system was designed, a large portion of the fluid system fittings and tubing were unable to be leak-checked under static conditions. In addition, the length of time for which the propellant feed systems operated ( 3 to $5 \mathrm{sec}$ ) made it difficult to leak check the total system while flowing. A flowing leak test, where cryogenic fluids were used in the liquid systems and gases were used in the gaseous systems, was performed. A flow test using the actual propellants when checking for leak detection is a dangerous exercise and is not recommended. The safety of the personnel performing the inspection is at risk. A substitution of inert cryogenics and gases (liquid nitrogen and helium) were used to check the system in order to remove the hazards of flammability. This allowed all of the systems to be inspected in conditions as near as possible to the actual operating conditions of pressure and temperature. To yield a more stringent test condition, these tests also took into account the transients associated with the operation of the system. During these tests personnel were located strategically around the system to perform visual and point source inspections. 


\section{Bubble Check}

The minimal detectable leak rate of bubble checking is typically on the order of $10^{-3}$ standard cubic inches per minute (scim). ${ }^{7}$ For LASRE, only a modest number of the fittings could be reached to apply this technique. Even though a fitting could be reached, there was no assurance that a full inspection could be performed. Using high-pressure helium gas as a substitute, this technique was applied during a pressure decay test on the tank and line leading to the main shutoff valve to check for leakage. Several leaks were detected on the hydrogen main feed line and downstream of the split to each side of the engine during transient testing. Application of this technique to the cryogenic flow tests is not practical because the bubble solution freezes on the joint under inspection.

\section{Ultrasonic Detector}

An ultrasonic leak detector was employed on LASRE early on in the program to evaluate leakage from fittings during both static and transient testing of the gaseous hydrogen system. This instrument measures the highfrequency pressure waves that emit from a small sonic gaseous jet. Its minimal detectable leak rate is on the order of $10^{-3} \mathrm{scim}$. This leak detector could only reach a limited number of fittings because of accessibility. It is not known if any significant leakage was detected using this instrument during static pressure tests. Background noise during the transient testing cycles rendered the ultrasonic leak detector ineffectual.

\section{Thermal Conductivity Detector}

A thermal-conductivity-based leak detector was also used for leak detection of LASRE. This is a small, inexpensive handheld device. It can detect low concentrations of leaking gas by measuring small changes in the air thermal conductivity. However, it is not gas-specific, and must be set for the specific gas being used for leak testing, such as helium. For this device to read correctly, the background environment must be steady (such as air) and there should be no contaminant gases in the region. Minimum detectable leak rate is comparable to bubble checking, about $10^{-3}$ scim. Accessibility to hidden components is better than with bubble checking and it does not get the system wet. This device was useful for locating a few leaking fittings, and for determining leaks through the vent valves and out the vent lines.

\section{$\underline{\text { Joint Bagging }}$}

The technique of joint bagging was attempted by LASRE. It was unsuccessful in obtaining any results because of the lack of means to adequately measure the bag volume and sample the volume captured. Lack of accessibility to much of the systems made this technique very impractical.

\section{Mass Spectrometer}

A mass spectrometer that was on loan from $\mathrm{KSC}$ was used by LASRE, but never as a point source leak detection instrument. The minimum detectable leak rate of the instrument is several orders of magnitude better than these other point source detectors. It has been successful in detecting leaks on the order of $10^{-7}$ scim, and is a little better in gaining accessibility. By attaching a wand to the sniffer line it can be used to probe into the volume up to the fittings in question.

\section{Systematic Detection Tools and Techniques}

The specialized instrumentation used for LASRE as systematic leak detectors were: pressure transducers, gas species detectors, and a mass spectrometer. Well calibrated and strategically placed, these highly specialized sensors can provide a wealth of information for assessing the environment in which the feed systems operate. A drawback of these techniques is that the coverage must be dense enough to be able to make conservative estimations about the overall leak rate of the system. With testing and familiarization a high degree of confidence can be achieved with these techniques for manned and autonomous programs that anticipate multiple flight tests.

\section{Hydrogen Tank Pressure Decay Leak Detection $^{8}$}

In order to infer the presence of fuel in the pod, a realtime pressure decay method was used to detect the overall hydrogen leakage from the wetted portion of the system while the operations were static. Conventionally, pressure decay leak detection takes a long time to perform, and is usually done during system checkout. A noticeable pressure drop in the gaseous hydrogen tanks during flight operation would indicate a large leak, or perhaps a thermal transient. However, due to the lack of flight-qualified hydrogen sensors, a pressure decay method was implemented for real time in-flight use. This method was for leaks from the hydrogen tanks and lines up to the main shutoff valve in a static mode only, and not for leaks in the hydrogen lines or during flow. 
In theory, hydrogen leak rate can be determined from the change in mass of hydrogen in the tanks $\Delta m_{H_{2}}$ as follows:

$$
\Delta m_{H_{2}}=\frac{V}{R}\left(\frac{P}{Z T}-\frac{P_{0}}{Z_{0} T_{0}}\right)
$$

Tank pressure (P) was measured by a pressure transducer. Hydrogen gas temperature (T) was measured by two redundant thermocouples mounted on probes inside the tanks and the data was averaged together for one reading. To obtain an accurate measurement of gas temperature under changing conditions, a tank surface measurement would have been inadequate. Tank volume (V) was assumed to be constant. Compressibility $(Z)$ was a function of $\mathrm{P}$ and $\mathrm{T}$, and the subscript 0 denotes initial conditions. $\mathrm{R}$ is the gas constant for hydrogen.

In software, digital low-pass filtering was applied to the $\Delta m_{H_{2}}$ signal, to remove high-frequency random noise and to facilitate data interpretation. The filter time constant was adjustable and was set by the user to obtain a readable signal, while preserving reasonable response time and quick recovery from data spikes. Magnitude limits were imposed to prevent telemetry data spikes from corrupting the calculation. The calculation could be configured for either hydrogen or inert helium as the working gas.

The ability to detect leaks depended on discerning small changes in pressure and temperature, which was a function of instrumentation resolution. The trace showed good stability under the varying ambient conditions of flight. Uncertainty analysis indicated that a mass loss of $0.15 \mathrm{lbm}$ or more could be detected. Ground testing, done by releasing controlled small amounts of gas from the tanks and observing the trace, showed that a mass loss as low as $0.03 \mathrm{lbm}$ could be detected.

In the control room, if a mass loss rate of greater than $0.03 \mathrm{lbm}$ was seen in 8 minutes or less, it would be considered a positive determination of leakage, and steps would be initiated to safe the system by dumping propellants overboard. This leak rate corresponds to about 4 percent of the nitrogen ground operations purge flow rate in the vicinity of the hydrogen tanks, or about 1460 scim. This was judged to be the minimum leak rate reliably detectable in a reasonable timeframe. However, it is still a substantial and potentially hazardous quantity of hydrogen and a quantity that is capable of locally forming combustible mixtures in the pod. Lower leak rates could possibly be detected over a longer period of time.

The hydrogen leak detection algorithm was a useful tool and the only available means of real-time hydrogen leak detection on LASRE, but could not be relied upon to detect all hazardous leaks. This algorithm could detect moderate to large tank leaks, or smaller leaks over a long period of time. It could not detect small but still hazardous leaks in a timely manner.

\section{Concentration Assessment Techniques}

It was determined through the interpretation of the industry and NASA safety practices that the acceptable limits of oxygen and hydrogen concentration for the flight safety of this particular flight test was to be less than or equal to 1 percent at any time the system was static. This represented one-quarter of the lower flammability limit providing a safety factor of four to the test. Post engine testing, the oxygen levels were allowed to reach 4 percent, but hydrogen acceptability limits were to remain unchanged. Exceeding these limits meant a violation of the safety of flight rules, and the program was not allowed to proceed to actual hot fire testing unless the violations were corrected.

To clearly interpret the concentrations measured so that proper assessment of the hazard can be accomplished, the purge flow rates must be known and flow paths characterized. The design of the nitrogen purge mass flow rate for the system was set to approximately 38,000 scim while conducting test operations. The purge rate by volume breakdown was approximately 24,000 scim for the canoe and 14,000 scim for the model. Based upon these purge rates, the maximum concentration allowable, and the assumption of achieving a homogeneous mixture, the maximumallowable leak rates could be established. The maximum-allowable leak rates, in order to maintain the 1-percent volume fraction for the hydrogen system, is 240 scim into the canoe. During the transients, the hydrogen system was not to leak more than 140 scim into the model. For the oxygen system, the maximumallowable leak rate was determined to be $140 \mathrm{scim}$ for the static period. The transient period maximumallowable leak rate for oxygen was $560 \mathrm{scim}$.

The concentrations of escaped fuel and oxidizer within the LASRE were assessed by field sampling the volume with gas species sensors. Commercial oxygen and hydrogen detectors are available for this purpose. Some detectors output partial pressures over the range of $0-100$ percent. Other types of detectors sense very 
low levels, typically 10-2000 parts per million (ppm), and that may or may not be within the range of sensitivity for adequately assessing leak rate acceptability. These detectors may also require a minimum oxygen concentration in the background for proper operation of the sensor element. The oxygenated background requirement may conflict with the use of flammable propellants for testing the system integrity.

Most detectors available are designed with the intention of being used in industrial applications operating at standard atmospheric conditions. Employment in a flight environment requires a significant qualification effort and calibration at reduced pressures and concentrations to determine range of detection and accuracy. This information is useful in understanding and determining mission flight safety rules. To compensate for altitude effects, some of these sensor packages may require an ambient pressure measurement unless a pressure compensation has already been integrated into the detector. Upon satisfactory completion of a thorough qualification test, sensors may be placed strategically within a vehicle in the hopes of providing adequate coverage to confidently assess the vehicle environment and overall leakage from the systems.

For the LASRE program, six hand-held industrial hydrogen detectors were used to help evaluate the health of the propellant feed system. Typical characteristics are $0-1000$ or $0-2000 \mathrm{ppm}$ hydrogen range, with an accuracy of 1 percent of the full-scale reading. These units were used in conjunction with a mass spectrometer on loan from $\mathrm{KSC}$ for a 3-percent gaseous hydrogen blowdown test to assess the gaseous hydrogen feed lines. All of the units used aspirators to draw samples from surface ports. The sample lines were teed, so that both the handheld units and the mass spectrometer could sample simultaneously. These locations are shown in figure 7 . The positions were chosen to represent those locations where leaking gaseous hydrogen were most likely to occur within the volume post-testing. All of the main feed lines and flow control valves existed below sample ports 4,5 , and 6 . Sample ports 1 and 2 were intended to catch any gaseous hydrogen coming up the sewer pipe and leaking from the main feed lines. Sample port 3 was intended to catch any leakage from the engine manifolds. The gaseous hydrogen tank was serviced to 4000 psi with certified 2.4-percent gaseous hydrogen in a helium balance. The failure criteria was observation of levels that exceeded $240 \mathrm{ppm}$, which represents 1 percent of the 2.4-percent gaseous hydrogen within the canoe volume. The nitrogen purge was not activated for the test because the handheld units required an oxygenated background. Background and noise levels measured from zero to ten ppm.

Figure 8(a) shows the transient data from the main flow test. The maximum concentration detected was approximately $67 \mathrm{ppm}$ with handheld unit no. 6 . Figure 8 (b) shows the transient data of the autosafe function, which empties the contents of each system individually through the engine. The maximum value attained for this test was approximately $170 \mathrm{ppm}$. Neither of these tests breached the maximum operating concentration of $240 \mathrm{ppm}$, which related to a local concentration in excess of 1-percent gaseous hydrogen. For both tests, lack of concurrence with the mass spectrometer values could not be rationalized, but it is speculated that there might have been time lag and sample line switching issues. Regardless, even the addition of the handheld units levels to mass spectrometer levels measured did not breach the $240 \mathrm{ppm}$ acceptability limit set for the test. There is no direct way to relate these measurements to a conservative estimate of leak rate given the small number of sample points. If the system were allowed to reach equilibrium, and more sample locations were available, an estimate of the mean concentration could be surmised. Using this surmised value and assuming that this is a homogeneous mixture at standard conditions within the canoe volume $\left(72 \mathrm{ft}^{3}\right)$, then multiplying by the percentage ratio of pure hydrogen gas to the test gas, dividing these results by the time period $(\sim 3 \mathrm{sec})$ of the main flow, and doing the necessary unit conversions; will result in an approximate leak rate from the system. Based upon the 1-percent accuracy of the handheld units used for this test, this is equivalent to a 20 -ppm measurement capability within the volume. If the system were allowed to stabilize after the main flow, the leak rate minimally detectable by this method would be approximately $50 \mathrm{scim}$. This leak rate was well within the limits of acceptability.

Onboard hydrogen detectors for in-flight assessment purposes were researcher requested, but not flight safety critical to the program. Commercial systems are available, but were not proven to be robust equipment with a history for this type of application. One such system was provided for the project that used a palladium-nickel sensor design developed by Sandia National Laboratories of Albuquerque, New Mexico, and had a temperature compensation control package. This system was taken to bench tests for calibration which would check out the useful pressure altitude range of the system and sensitivity of the sensors. Calibrations were performed with uncertified 
customized nitrogen and hydrogen mixtures. The preliminary results of these tests were encouraging, but as a result of schedule issues, it only was accepted to use these instruments as a discrete indicator of a hydrogen leak. Once the system was integrated into the pod, the difference in instrumentation setup from what was used on the calibration bench in some way corrupted the signals. The problems were elusive and went unresolved. The system was disregarded as an indication of in-flight hydrogen detection, which added a higher level of risk to the program.

As stated previously, the oxygen sensors chosen for implementation were put through rigorous qualification testing before they could be employed. The strategy behind their emplacement (see figure 5) was as follows. Sensors 1 and 2, being forward of the gaseous hydrogen tanks, were intended to verify purge and canoe hull integrity. Sensors 3 through 8 monitored oxygen migrating with the purge down the length of the canoe and flowing over the gaseous hydrogen tanks and main feed lines. Sensor 9 was to verify that the model purge was active and that there was no oxygen intrusion through the model hull. Sensor 10 was the liquid oxygen spill monitor. Sensors 11 and 12 monitored the atmosphere around the manifolds where both the gaseous hydrogen and liquid oxygen main feed lines split into the engine block.

The detectors performance was surprising and proved better than expected. As a confidence check of the instruments before activation of the nitrogen purge, the oxygen sensors were compared to standard atmospheric conditions for nominal operation checks. After acceptance checks, an inert environment was established. Figure 9 shows a time history response of the oxygen sensors (with the canoe and model volumes inert) to the flight dynamics of takeoff, through establishment of an altitude at $31,000 \mathrm{ft}$.

Figures 10(a)-(d) show the correlation of liquid oxygen prechill and main valve flow startup with oxygen detection sensor data. Parameter PRECHILL represents the prechill valve command and parameter LOXMAIN is the main valve command. Figure $10(a)$ is of oxygen leakage that was detected during a first main flow through the system from a ground test. Figure 10(b) shows oxygen leakage detected during the second main flow through the system from the same ground test. After the first, and sometimes second, main flow was executed, the autosafing function was executed to empty the tanks of their contents. Figure 10(c) demonstrates the detection of oxygen leakage that occurred during the oxygen autosafing process from a ground run. Based upon these results, the purge rate was increased. This increase was expected to improve the purge effectiveness and flight testing resumed. Figures 10(d) and $10(\mathrm{e})$ are the oxygen leakage detection data from that flight, in which a single main flow and then the autosafing function were executed, respectively.

As previously stated, the oxygen sensors had an uncertainty of approximately 0.1 percent at mean sea level (see figure 6). Using this uncertainty as the minimum detectable oxygen concentration by the sensor, knowing the volume of the model $\left(51 \mathrm{ft}^{3}\right)$, and assuming that a 0.1 -percent concentration that was measured represented a homogeneous mixture throughout the model volume; an estimate of the minimal detectable leak rate from the system could be made. The minimum detectable leak rate of liquid oxygen is estimated to be approximately $0.04 \mathrm{in}^{3}$ per sec. From the data in figure 10(a), a conservative approximation of the homogeneous concentration peak is 1.6 percent within the model volume after a first main flow of liquid oxygen lasting 3 seconds. The leak rate of liquid oxygen from the system for this test is estimated to be 0.63 in. ${ }^{3}$ per sec of liquid oxygen. From the data in figure 10(e), a conservative approximation of the homogeneous concentration peak is 3.5 percent within the model volume after a liquid oxygen autosafe blowdown test lasting approximately 30 seconds. The leak rate from this test is approximately $0.14 \mathrm{in}^{3}$ per second of liquid oxygen. Each of these test runs show leak rate data representing a composite leak rate from a transient system. This is what made the identification of the leak source such a difficult task. It is believed that the quantity of liquid leakage that has been estimated, when split up by the number of possible leak paths from the system, was not detectable by visual inspection techniques. This data reinforces the position that sensitive instrumentation, when strategically positioned, can provide a wealth of information on the health of the systems.

\section{Helium Signature Test}

NASA KSC has performed a significant amount of research on the use of a mass spectrometer for leak detection of the Orbiter main engines and propellant feed lines. Of notable interest is the technique that was developed for leak detection of the main engines and feed lines, known as the "Helium Signature Test (HST)." The minimal leak detection capability achieved with this technique, as applied to the Orbiter propellant feed systems and the Space Shuttle main engines purge rate, has been measured to be on the order of $6.0 \mathrm{scim}^{7}$ 
HST is a two-step process that characterizes leakage from the system, and then using actual leakage data, allows one to extrapolate what the operational equivalent leakage may be. Applying the purge rate of the model to the results of the signature test, one can ascertain the flammability hazard.

The first step of characterizing leakage is to insert gaseous helium at known flow rates into a purged control volume, using a wand at predetermined locations where leakage is most likely to occur, i.e. joints, instrumentation, section fittings, and valves (see figure 11(a)). The mass spectrometer then pulls samples of the purged environment from a fixed effluent location for each insertion point, and characterizes the mass spectrometer response for a known leak rate at that point. This data is used to develop calibration curves for the known injected leak rate.

The second step involves applying back-pressure with gaseous helium to the feed system and sampling the purge effluent from the same fixed effluent location that was used during the characterization test points (see figure $11(\mathrm{~b})$ ). Once the readings have stabilized and are recorded, several more back-pressure settings are used to add more spread to the data points. The back-pressure data is then used with the characterization data to generate a response curve of leakage for given operational pressures. In theory, it is then possible to extrapolate what the overall leakage will be at the operating pressures of the system (see Appendix).

The mass spectrometer instrument was used only for the 3-percent gaseous hydrogen blowdown test discussed previously and the HST. Figure 12 shows the approximate locations within the pod volume where gaseous helium was inserted to simulate leakage for the HST. A panel near the aft left-hand side was cracked open ( $\sim 6$ in. vertical slit) to act as a sink for the purge. The probe for the mass spectrometer was inserted into this slit.

The data from the HST was separated into the canoe and the model. Only the model data is fully analyzed in this paper because the model volume is where the most significant potential for a hazard exists by having the liquid oxygen and gaseous hydrogen systems coexisting. The model gaseous helium insertion data for the characterization portion of the test is plotted in figure 13(a). The average of the data was computed and plotted as well. A linear curve fit of the average data was generated and overlays the real data. The worst-case linear curve fit was generated from determining the equation of the line through the $y$-intercept (the baseline) and the worst-case data point. The difference between the average and the worst case is used as the uncertainty of the data set. The data plotted in figure 13(a) shows a tight grouping that lends credibility to the statement that a leak at any location along the system within the model volume will be readily detectable by the mass spectrometer during the backpressure portion of the test.

Gaseous helium was then applied through the engine, using special throat plug fittings. Samples were taken at several back-pressure settings in an attempt to provide some data spread. Using the concentrations measured during the gaseous helium back-pressure test, the leak rate at each back-pressure point can be correlated to the gaseous helium insertion rates average leak rate equation to estimate the whole system leak rate from the back-pressure setting. This data is shown in figure 13(b) with the uncertainty shown by the vertical bars. It is important to remember for the LASRE test case that the leakage measured during the gaseous helium backpressure test includes any possible leakage from the liquid oxygen system. This is a result of the inability to isolate the liquid oxygen system from the gaseous hydrogen system for the gaseous helium back-pressure test. It means that the results from the back-pressure test, as related to the resulting gaseous hydrogen leak rate computations, are a conservative estimation, because they include any leakage from the liquid oxygen system, but the extent of the liquid oxygen contribution was not quantifiable.

Once the gaseous helium leak rates have been calculated, it is possible to relate the gaseous helium leak rates to gaseous hydrogen leak rates. This can only be achieved if a fixed-geometry choked orifice flow is assumed. This method is detailed with application of the actual data in the appendix, given the known mass flow rate of gaseous helium and its source pressure and properties, it is possible to calculate the approximate size of the leak orifice based upon these assumptions. Then, knowing the leak orifice size, and the gaseous hydrogen system operating pressure and properties, one can calculate what the equivalent gaseous hydrogen mass flow rate is for this same gaseous helium leak rate. The results of this conversion are shown in figure 13(c).

Now having an estimation of the leak rates from the gaseous hydrogen system and knowing the purge flow rate, the hazard can be scaled. This is accomplished by taking the gaseous hydrogen leak rate and dividing it by the purge mass flow through the model. This, of course, assumes a homogeneous mixture throughout the model volume. 
For the LASRE experiment, the main flow cycle was scheduled to run for only three to five seconds. Team consensus was that the volume would have remained inert and begun to nearly completely purge the leakage which occurred during the test within a short amount of time thereafter. So, a better estimation of the true hazard is to take the leak rate estimated and integrate it over the three seconds of main flow. This quantity, in proportion to the model volume, is a better assessment of the gaseous hydrogen concentration hazard. The results of this calculation are shown in figure 13(d).

\section{Pressure Transducers}

It is speculated that the ambient pressure sensor that monitored the pressure of the volume inside the model detected cryogenics leaking during the prechill and main flow. Figure 14(a) shows ground run data, beginning with the command of the prechill valve PRECHILL, that reveals a very low-amplitude, highfrequency noise signal present on the pressure transducer signal that samples the pod internal pressure. Once the main flow valve (LOXMAIN) was commanded closed, the noise component on the signal trace (PODPRES) disappears. This event was observed routinely when cryogenics flowed through the oxygen system and only when the volume was closed up. Figure 14(b) shows the in-flight data of the same phenomenon with the amplitudes a bit less than the ground data. The low-frequency high-amplitude signal that this noise is superimposed upon, is a result of the purge performance (i.e. - liquid nitrogen flowing through a heater exchanger to vaporize it before injection into the volumes). No other correlation to any other system events could be made with this data.

In summary, table 1 displays leak detection techniques, brief descriptions, notes on limitations and considerations, and some leak rate detection quantification broken into the two classifications discussed previously. It also shows conservatively calculated quantification of the leak rates detectable by the techniques employed on LASRE as compared to past experiences and test results. Quantification of the leak rates is very difficult to achieve with the point source measurement techniques and there was very little historical precedence available on the leak rate quantification of the systematic techniques. Note that the HST LASRE results are not indicative of the minimal detectable leak rates for the system and instrumentation configuration because there was no characterization done for this technique. Only the Pressure Decay Monitor Algorithm had characterization testing done in order to determine its minimal detectable leak rate based on the instrumentation resolution and uncertainty. The minimum detectable leak rates from the oxygen system is based on oxygen sensor resolution, uncertainty, and the assumption of a homogenous mixture that is based upon concentration field measurements within the model volume. 


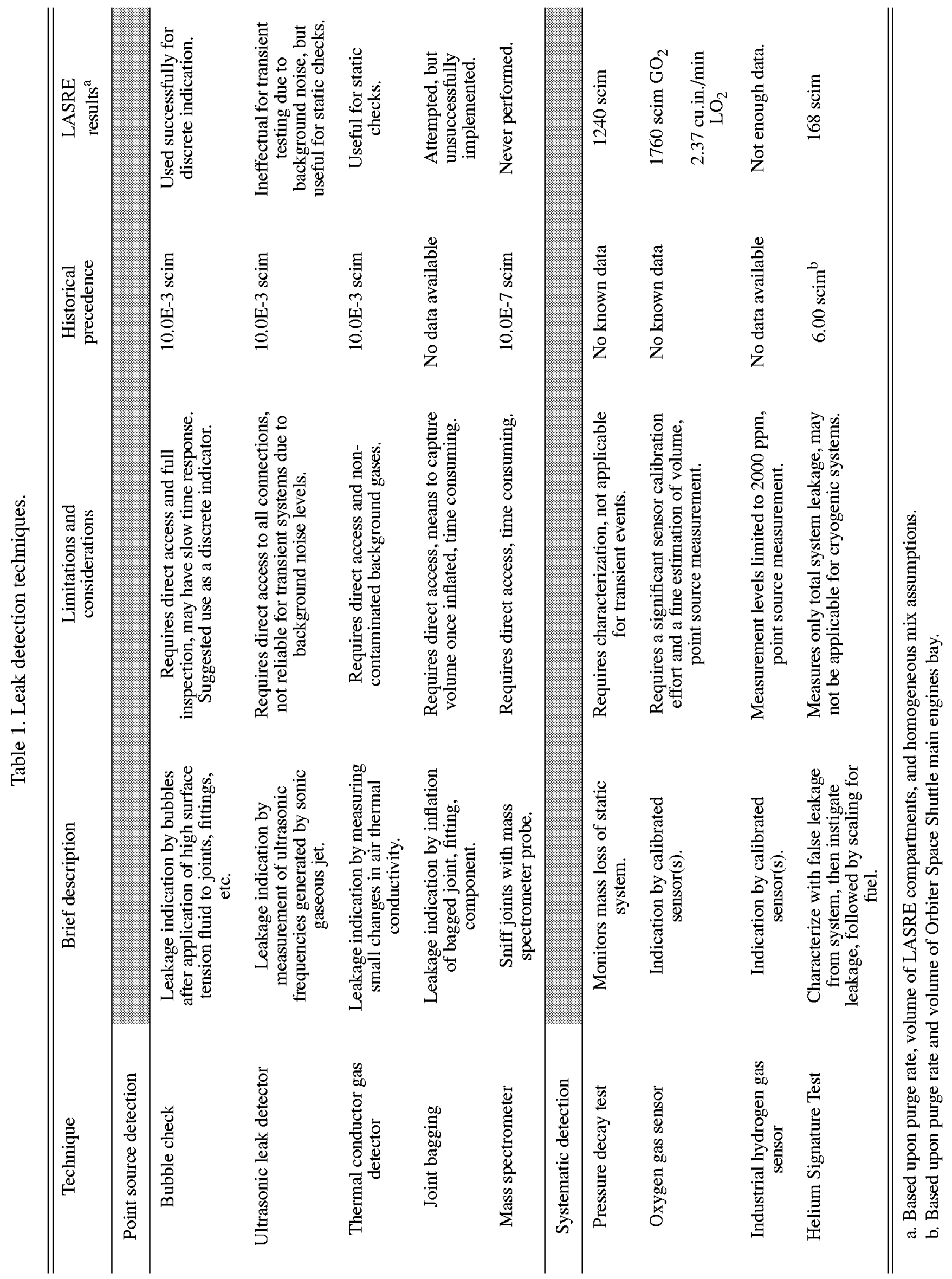




\section{Concluding Remarks}

This document describes the results of propellant feed systems leak detection tools and techniques applied as part of the validation testing of the Linear Aerospike SR-71 Experiment (LASRE) program flown at NASA Dryden Flight Research Center, Edwards, California. This testing was conducted in order to meet the safety requirements associated with the use of combustible and detonable gases aboard a piloted aircraft. The goal of this paper is to provide an assessment of leak detection techniques for hazard mitigation of hydrogen-oxygen propellant feed systems, based upon the experiences of the LASRE program team. This document also provides some insight into strategies that may improve leak detection for the success and increased safety of other programs, and provides suggestions for future research.

The conclusions and suggestions based upon the LASRE experience are as follows:

\section{Propellant Feed Line Design Considerations}

- Build in provisions to leak check the majority of a fluid system lines and fittings under static conditions. There was no provision built into the LASRE design for blocking valves close to the end of the feed lines, leaving the system open to ambient pressure from the source once the main blocking valve and flow-control valves were opened. This feature would have made it possible to do systematic static leak tests on the system. In particular, the design lacked the means to determine whether the liquid oxygen leakage was coming from the main feed lines upstream of the main and prechill junction, the prechill line, or downstream of the main and prechill junction. It also left no means to isolate the liquid oxygen system from the gaseous hydrogen system when the Helium Signature Test was being conducted.

- Successfully isolating the feed systems would reduce the instrumentation requirements necessary to assess the health of the systems and further reduce the hazards. Design the individual systems such that the oxidizer, fuel sources, and feed lines are separated by as much purged space as is reasonably allowable. If possible, isolate these systems with sealed boundaries and create separate purge paths. LASRE did take advantage of this isolation in the sense of the gaseous hydrogen being stored in a compartment separate from the liquid hydrogen and the intention of the design was to have the purge operate as two separate flowpaths. A physical boundary existed between the canoe and model, with the exception of the sewer pipe, which did not preclude liquid oxygen from dripping from its feed lines down into the compartment where the gaseous hydrogen was housed. A plate over the end of the sewer pipe with feed-throughs would have been an easy isolation solution early on in the buildup phase that would have added confidence to the system.

Purge

- An acceptable leak rate must be clearly defined and is based predominantly upon the mass flow rate of the purge system. As a rule of thumb, size the purge for the volume accordingly, so that a high-enough Reynolds number is generated to ensure turbulent flow for all phases of operation. This procedure (or high Reynolds number) enhances the rate of dilution to bring the mixture to an inert state and transports it from the volume quickly. This would also maximize the acceptable leak rate, which would make the validation of the systems that much easier to achieve. The negative impact is that it might require more stores to be carried than initially planned. For LASRE, the volume changeout rate was 1.5 volumes per minute for ground operations. At test altitude $(\sim 50,000 \mathrm{ft})$, this changed favorably to nearly 10 volumes of changeout per minute which was encouraging.

- It is desirable to characterize the purge and validate leak detection techniques by introducing quantified leaks. This is accomplished by activating the purge with the system in the configuration intended for nominal operation and inserting known leak rates into the volume, one at a time until stable data is generated. Enough source locations should be attempted to convince one that any leakage from the propellant systems will be indicated by the detection system and identify flowpath patterns and characteristics. None of this was conducted by LASRE until the Helium Signature Test was conducted, and as a result it indicated a purge flowpath from the model into the canoe when the canoe's manual vent was opened. This was not the intention of the original design and increased the danger of the system operation by bringing together purge laced with oxygen and hydrogen. It was then the intention not to operate the vent unless an overpressure was eminent to the pod.

- Be sure to re-characterize the limits of the system when changing the purge settings because the new settings may not have achieved the desired response. In the case of LASRE, it was assumed 
that increasing the purge mass flow rate between the last successful ground test and the following flight test would improve the performance and safety of the system operation. Unfortunately, these good intentions might have contributed to unfavorable results. It is speculated that the $\mathrm{LO}_{2}$ leak indication from the flight data was caused either by the resulting change in the purge flow path, where indications from oxygen sensors of previous ground run data were not seeing the oxygen leak at its full potential, or that the liquid oxygen system had in some way degraded from the last ground test. The purge mass flow rate change, without characterizing the results with a ground test, added a variable that could not be accounted for in the flight test results.

\section{Techniques and Tools}

- Visual inspections methods are valid for gross leak checks of cryogenic systems only. Extremely low flow rate leakage from multiple cryogenic fittings, which vaporize nearly instantaneously, can contribute significantly to an overall violation. This was where LASRE repeatedly made its mistakes. The inspection team was looking for some kind of visual indication during flow tests. Most likely, they could not detect these with the naked eye.

- Bubble checking, joint bagging, and ultrasonic detectors were not sufficient leak detection techniques to meet acceptability requirements for LASRE.

- The pressure decay algorithm must be applied with caution. The resolution of the instrumentation limits this technique to detecting only gross leakage. The greater the tank volume in question, the greater the leakage before detection by the algorithm.

- Commercially available hydrogen detector systems show promise, but in this application they remain to be proven. Considerable research in qualification and validation testing still needs to be done to improve this technology before achieving integration. The full range of altitude as a requirement needs to be met as well.

- Commercially available oxygen sensors demonstrated good leak detection performance, but a thorough calibration and qualification of these sensors are a prerequisite.

- Using high-precision pressure transducers that measure ambient environmental conditions, it may be possible to detect what might be cryogenics leaking through fittings and boiling off. The use of multiple sensors might allow approximation of the location of the leak source. More research is needed to validate this technique. This method may be limited to single-source leak detection. To improve accuracy in determining locations, the purge might need to be non-operational once the environment is inert.

- The location and the quantity of sensors is critical for gathering the optimum amount of information and assessing the health of the system. The philosophy generated from the LASRE experience was to: (1) place a higher number of oxygen sensors along the fuel lines and fewer in the surrounding regions of the oxidizer lines and (2) place a higher number of hydrogen detectors along the oxygen lines and fewer in the proximity of the hydrogen systems. The danger to either system exists when one component is above the flammability limits and in close proximity to its complement system. It is unlikely that a high concentration of fuel or oxidizer will persist at any location remote from the leak source as long as a validated purge is doing its job. Therefore, any leakage from one system may never reach the other or do so at levels below flammability. This does not preclude the need to validate leak detection capability if you have a leak of oxygen, hydrogen, or both. This may or may not be acceptable depending upon the philosophy of the design and test team and the risk levels associated with the program.

- Because transient cryogenic systems are so difficult to leak check, a total mass capture technique might be employed to quantify the leak rate of the system. This could be achieved by capturing purge gas vented from the volume, beginning from the event start until a portion of time after the event. One suggestion would be to perform this capture for the time necessary to complete at least one volume exchange. Then knowing the timespan of the event, it would be possible to estimate the total mass loss during the event from a mass spectrometer sample of the mass captured.

- Although the fundamental theory behind the HST technique makes sense, further research is needed to validate the assumptions made and quantify the accuracy. It was noted that during the LASRE HST, the effluent from the cracked panel was stratified. For improved accuracy on the effluent measurements, a total mass capture of steady state conditioned effluent might be done and then a mass 
spectrometer reading performed on this total sample. A suggestion for mass capture would be a large vacated bottle or simply a bag to be filled and then samples withdrawn.

- The HST data, supported by 3-percent blowdown data, lent confidence that the LASRE gaseous hydrogen feed lines met acceptability criteria. The design of the feed systems do not allow for separation of the gaseous hydrogen system from the liquid oxygen systems during the back-pressure portion of the Helium Signature Testing. As a result of this design shortcoming, it is speculated that the results are composed of leakage from both feed systems. The analysis of the data is presented as leakage from the gaseous hydrogen system only and believed to be a conservative estimation based upon this information.

- The HST was effective for characterizing leakage from the liquid oxygen system because it does not have the ability to replicate the transient effects of operating the liquid oxygen system. It is believed that thermal shock and loading issues inherent to the use of cryogenics cannot be adequately addressed by the results of the back-pressure portion of the test.

- The detected leak rates by the HST at lower source pressures may not actually linearly extrapolate to a higher source pressure. The extrapolation may or may not be an appropriate assumption, depending on the flow regime, dominant physics of the leak, and whether the leakage is linear as a result of loading.

\section{$\underline{\text { References }}$}

1" Safety Standard for Hydrogen and Hydrogen Systems," NASA NSS 1740.16, Office of Safety and Mission Assurance, Washington, D.C., 1995.
2"Safety Standard for Oxygen and Oxygen Systems," NASA NSS 1740.16, Office of Safety and Mission Assurance, Washington, D.C., 1995.

3"Ignition and Thermal Hazards of Selected Aerospace Fluids," NASA JSC White Sands Test Facility, RD-WSTF-0001, 1988.

4" Ignitability of Hydrogen/Oxygen/Nitrogen Mixtures at Reduced Pressures," NASA JSC White Sands Test Facility, TR-243-001, 1980.

${ }^{5}$ Corda, Stephen, Richard C. Monaghan, Leonard S. Voelker, Griffin P. Corpening, Richard R. Larson, and Bruce G. Powers, Flight Testing the Linear Aerospike. SR-71 Experiment (LASRE), NASA/TM-1998-206567, September 1998.

${ }^{6}$ Ennix, Kimberly A., Griffin Corpening, Michele Jarvis, Harry Chiles, "Evaluation of the Linear Aerospike SR-71 Experiment (LASRE) Oxygen Sensor," AIAA-99-4815, 9th International Space Planes and Hypersonics Systems and Technologies Conference, Norfolk, Virginia, November 1999.

${ }^{7}$ Bilardo, Vincent J., Jr., and Francisco Izquierdo, "Development of the Helium Signature Test for Orbiter Main Propulsion System Revalidation Between Flights," AIAA-87-0293, AIAA 25th Aerospace Sciences Meeting, Reno, Nevada, January 12-15, 1987.

${ }^{8}$ Mizukami, Masashi, Griffen P. Corpening, Ronald J. Ray, Neal Hass, Kimberly Ennix, and Scott $M$. Lazaroff, Linear Aerospike SR-71 Experiment (LASRE): Aerospace Propulsion Hazard Mitigation Systems, NASA TM-1998-206561, July 1998. 


\section{Appendix - Helium Signature Test Leak Rate Computation}

The following calculates the worst-case leak rate from the gaseous hydrogen system at operating pressures based upon the leakage measured from the gaseous helium back-pressure test and the calibration curves generated by the characterization test. The zero point is forced through zero, again providing a worst-case condition (background noise is not subtracted).

Using the line equation, $y=m x+b$ and the 0 slpm and 3.635 slpm points (worst-case slope from figure 13(a)) for the 60 psia gaseous helium backpressure results:

$$
\begin{aligned}
\mathrm{m} & =\left(y_{2}-y_{1}\right) /\left(x_{2}-x_{1}\right) \\
& =(6530-335) /(3.635-0) \\
& =1704.26
\end{aligned}
$$

$\mathbf{b}=0$

$y=780$ (maximum leakage seen during GHe backpressure test@60 psia)

$x=(y-b) / m=(780 / 1704.26)=0.4577$ slpm or $27.923 \mathrm{scim}$.

This leak rate is then correlated to a gaseous hydrogen leak at operating pressure using the information provided by Tibor Lak of Boeing, Downey, California. This equation is an approximation that assumes the leak path(s) to be small and choked flow occurs at the exit plane(s). The simplified coefficient for helium is 0.21 and for hydrogen is 0.14 .

$\mathrm{G}_{\mathrm{He}} @ 70^{\circ} \mathrm{F}+14.7 \mathrm{psia}$,

$\rho_{\mathrm{GHe}}=\mathrm{P} / \mathrm{RT}$

$=\left(14.7 \mathrm{psia} \times 144 \mathrm{in}^{2} / \mathrm{ft}^{2}\right) /\left(386.18 \mathrm{lbf} \times \mathrm{ft} / \mathrm{lbm} \times{ }^{\circ} \mathrm{R} \times\right.$ $\left.530^{\circ} \mathrm{R}\right)=0.01034 \mathrm{lbm} / \mathrm{ft}^{3}$

$\mathrm{GH}_{2} @ 70^{\circ} \mathrm{F}+14.7$ psia,

$\rho_{\mathrm{GH}_{2}}=0.00515 \mathrm{lbm} / \mathrm{ft}^{3}$
Using the standard mass flow rate obtained above,

$$
\begin{aligned}
\text { mdot }_{\mathrm{GHe}} & =\rho \mathrm{GHe} \times \mathrm{mdot}_{\mathrm{GHe} @ \mathrm{std}} \\
& =0.01034 \quad \mathrm{lbm} / \mathrm{ft}^{3} \times(27.923 \mathrm{scim}) / \\
\left(1728 \mathrm{in} .^{3} / \mathrm{ft}^{3} \times 60 \mathrm{sec} / \mathrm{min}\right) & \\
& =2.785 \times 10^{-6} \mathrm{lbm} / \mathrm{sec}
\end{aligned}
$$

The theoretical orifice size is calculated next, based upon the mass flow rate.

For the gaseous helium,

$$
\begin{aligned}
& \begin{aligned}
& \mathrm{Cda}=\left(\text { mdot } \times \mathrm{T}^{1 / 2}\right) /(0.21 \times \mathrm{P}) \\
&=\left(2.785 \times 10^{-6} \mathrm{lbm} / \mathrm{sec}\right) \times\left(530^{\circ} \mathrm{R}^{1 / 2}\right) /((0.21) \times \\
&\left.\left(60 \mathrm{lbf} / \mathrm{in} .{ }^{2}\right)\right) \\
&=5.089 \times 10^{-6} \text { in. }^{2}
\end{aligned}
\end{aligned}
$$

This is then correlated to a gaseous hydrogen leak at operating conditions ( 600 psia),

$\operatorname{mdot}_{\mathrm{GH}_{2}}=\left(5.089 \times 10^{-6}\right.$ in $\left.\times 0.14 \times 600 \mathrm{psia}\right) /$ $\left(530^{\circ} \mathrm{R}-\right)$

$$
=1.857 \times 10^{-5} \mathrm{lbm} / \mathrm{sec}
$$

the equivalent flow rate at standard conditions is,

$$
\begin{aligned}
\operatorname{mdot}_{\mathrm{GH}_{2} @ \mathrm{std}} & =\left(1.857 \times 10^{-5} \mathrm{lbm} / \mathrm{sec} \times 1728 \mathrm{in}^{3} / \mathrm{ft}^{3}\right. \\
\times 60 \mathrm{sec} / \mathrm{min}) /\left(0.00515 \mathrm{lbm} / \mathrm{ft}^{3}\right) & \\
= & 373.83 \mathrm{scim}
\end{aligned}
$$

This can then be correlated with the purge rate to estimate the hydrogen volume fraction of,

$$
\text { percent } \begin{aligned}
\mathrm{H}_{2} & =\mathrm{Q}_{\mathrm{GH}_{2}} / \mathrm{Q}_{\text {purge }} \\
& =374 / 14,000 \\
& =2.67 \text { percent (assuming homogenous } \\
& \text { mixture) }
\end{aligned}
$$




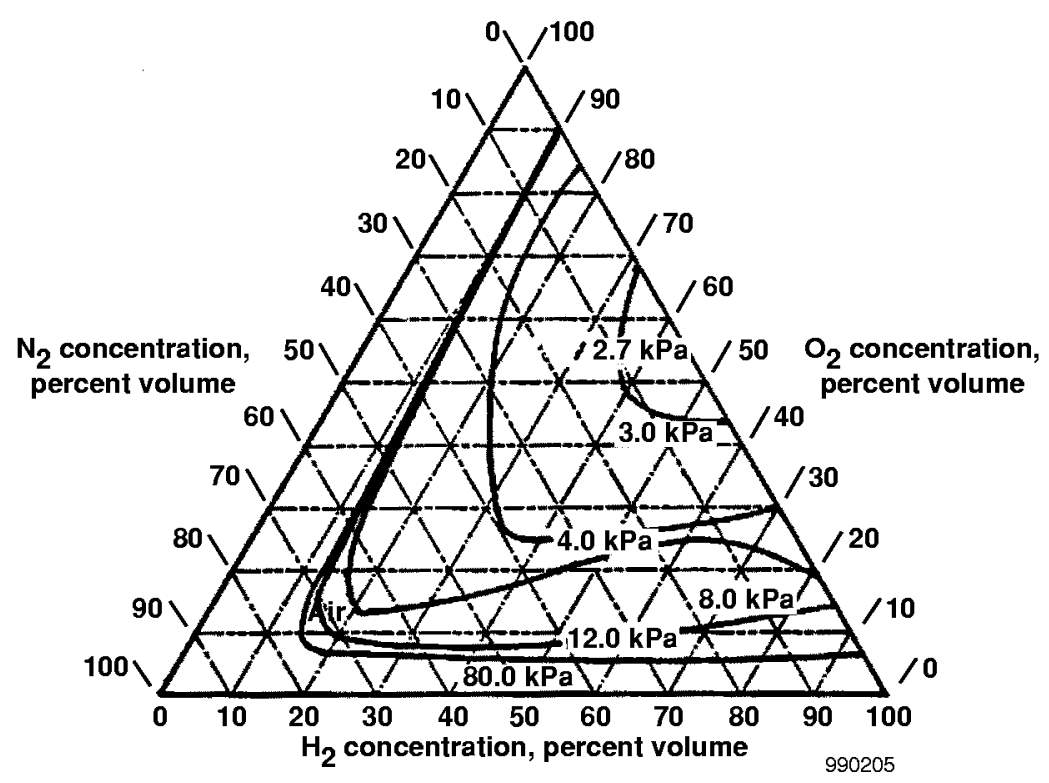

Figure 1. Flammability limits of hydrogen-oxygen-nitrogen mixtures at reduced pressures.

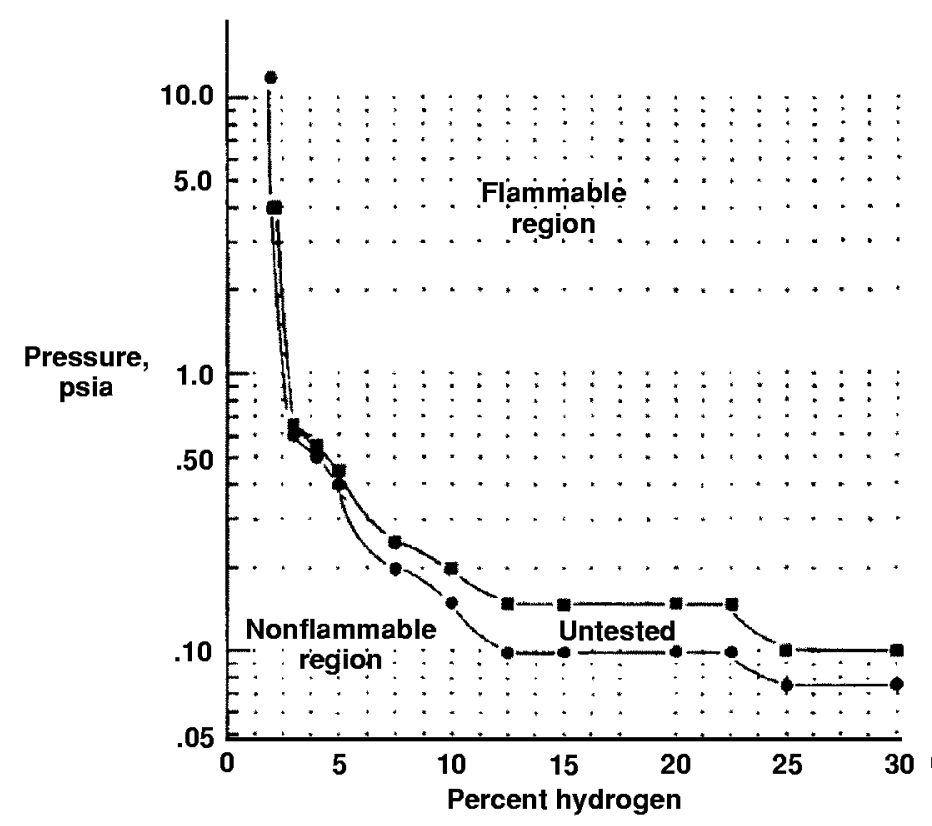

(a) $240 \mathrm{ft}^{3}$ chamber.

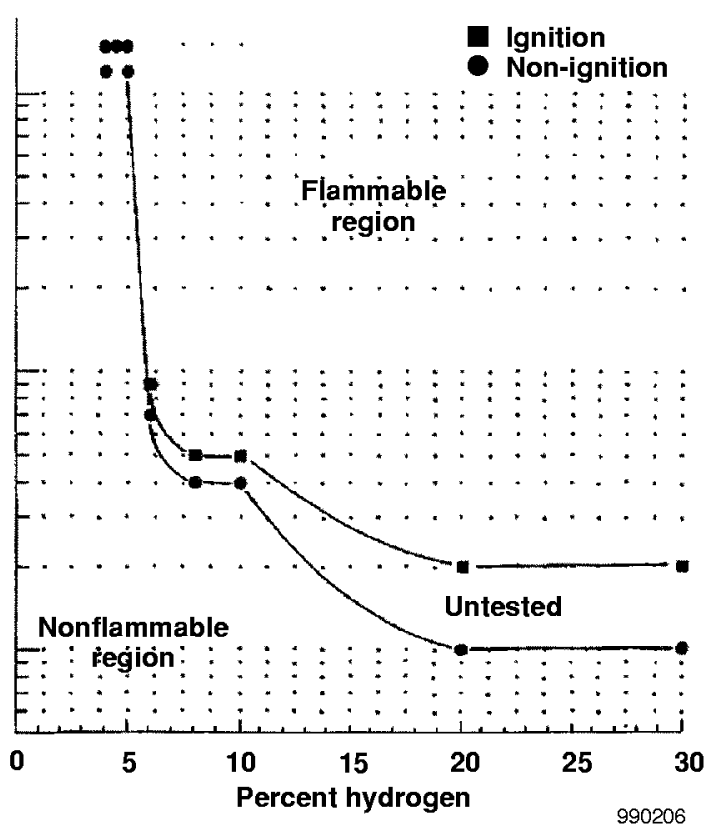

(b) $10 \mathrm{ft}^{3}$ chamber.

Figure 2. Ignition pressure limit with the standard excess oxygen and hydrogen mixtures. 


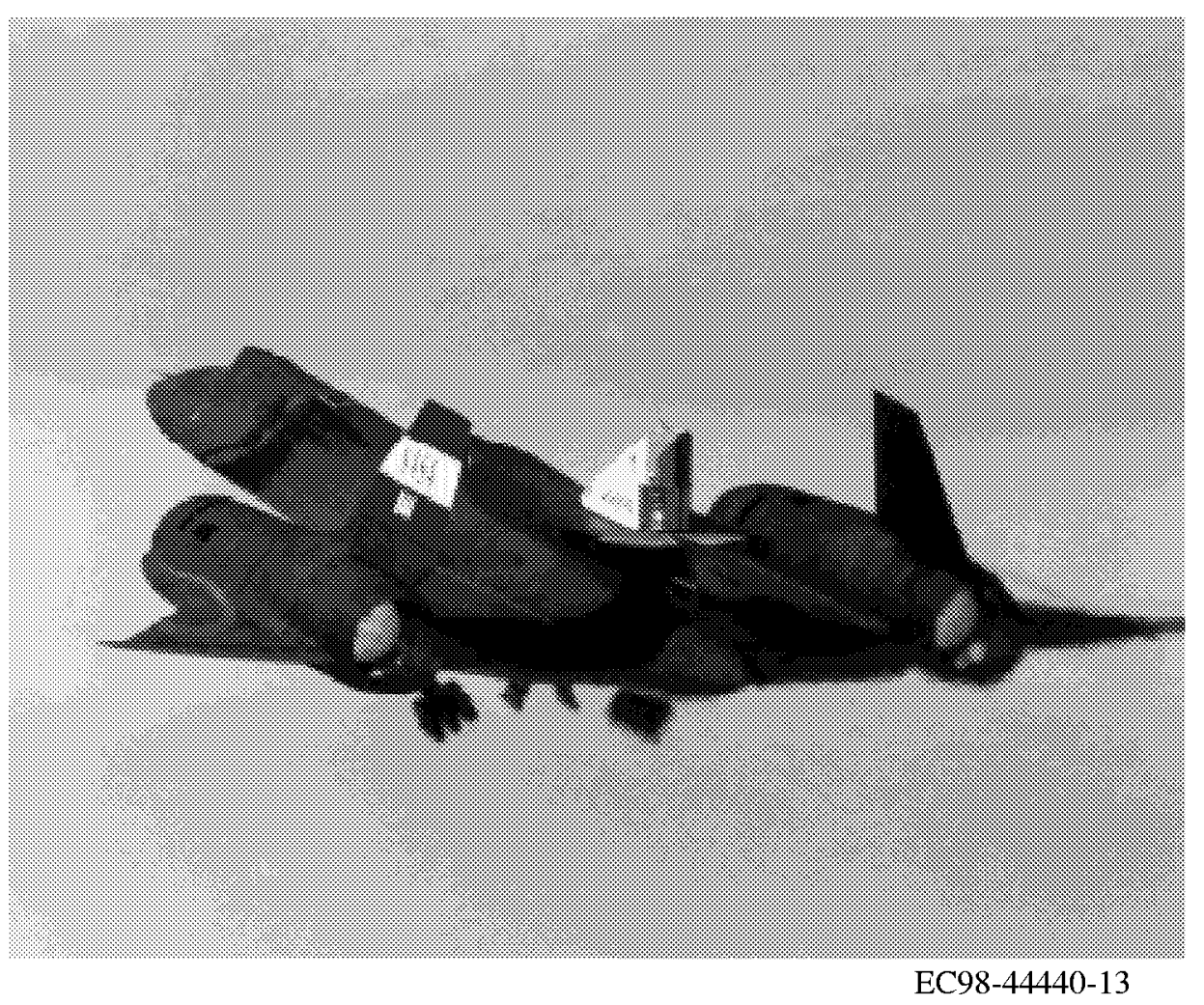

Figure 3. LASRE flight experiment.

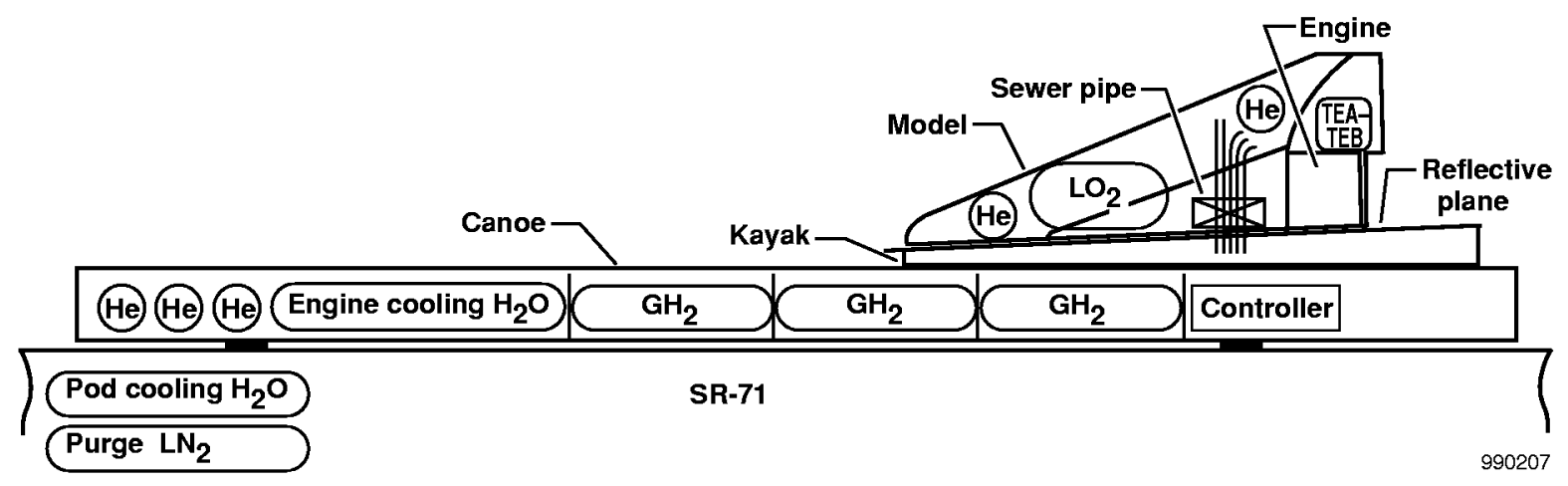

Figure 4. LASRE systems general layout. 
Model, top view

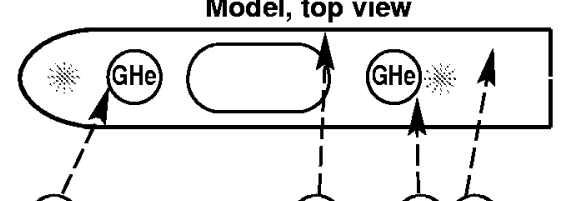

9

9

(10)

(11)(12)

(\#) Oxygen sensor

Purge source

Pod, side view

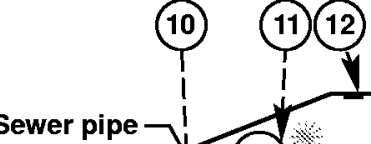

Sewer pipe

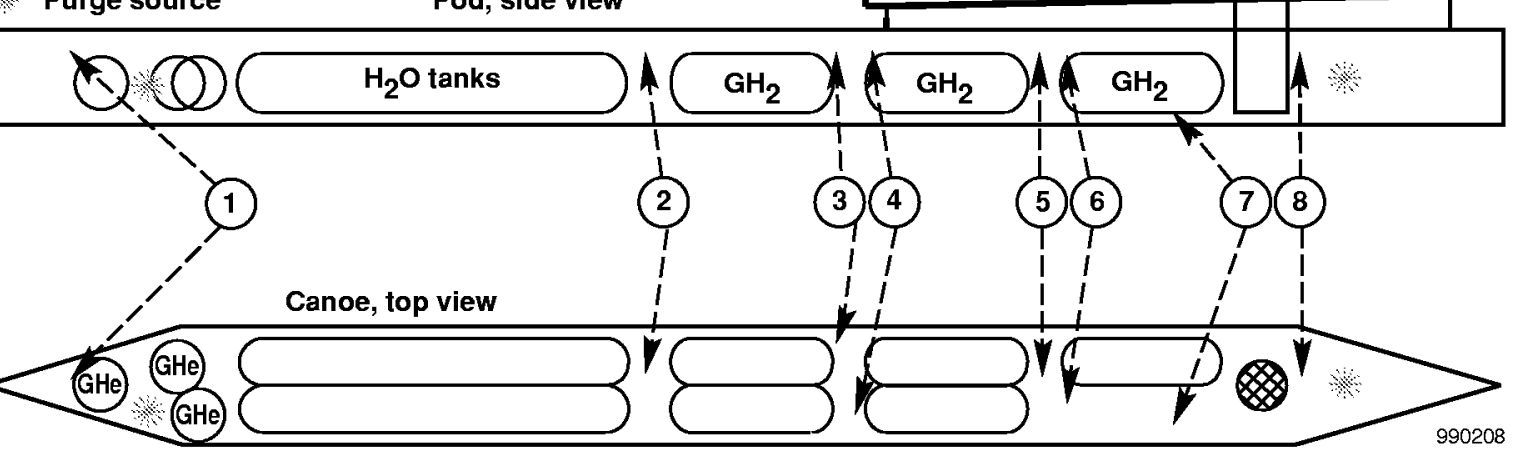

Figure 5. Oxygen sensor location.

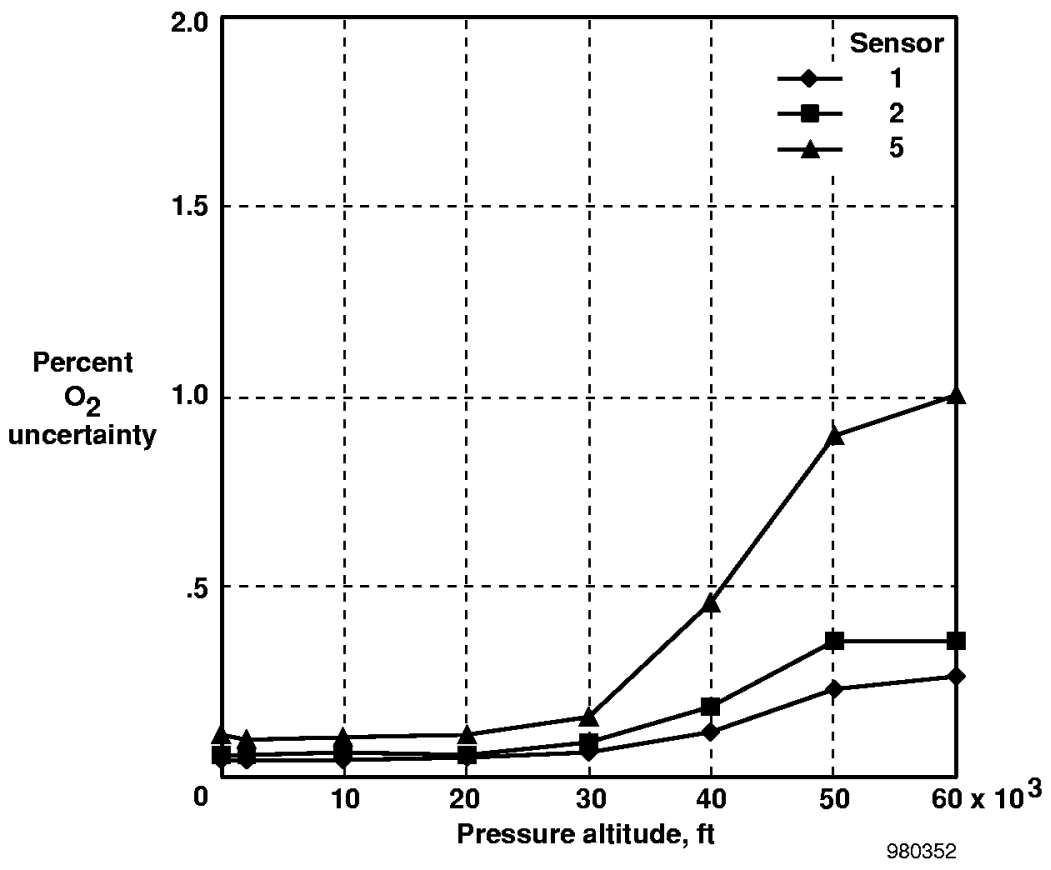

Figure 6. Oxygen sensor uncertainty at altitude. 


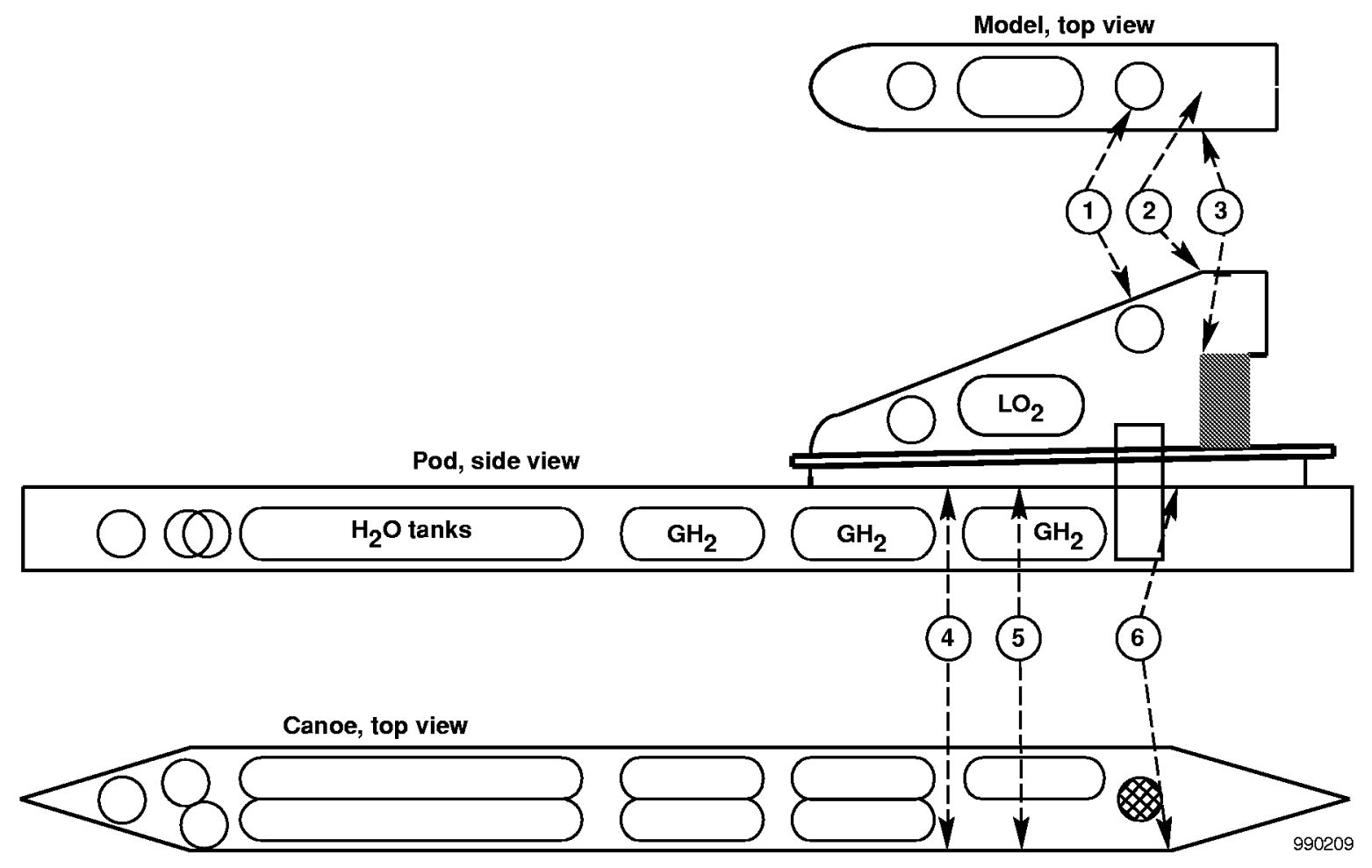

Figure 7. Three-percent gaseous hydrogen sample port locations. 


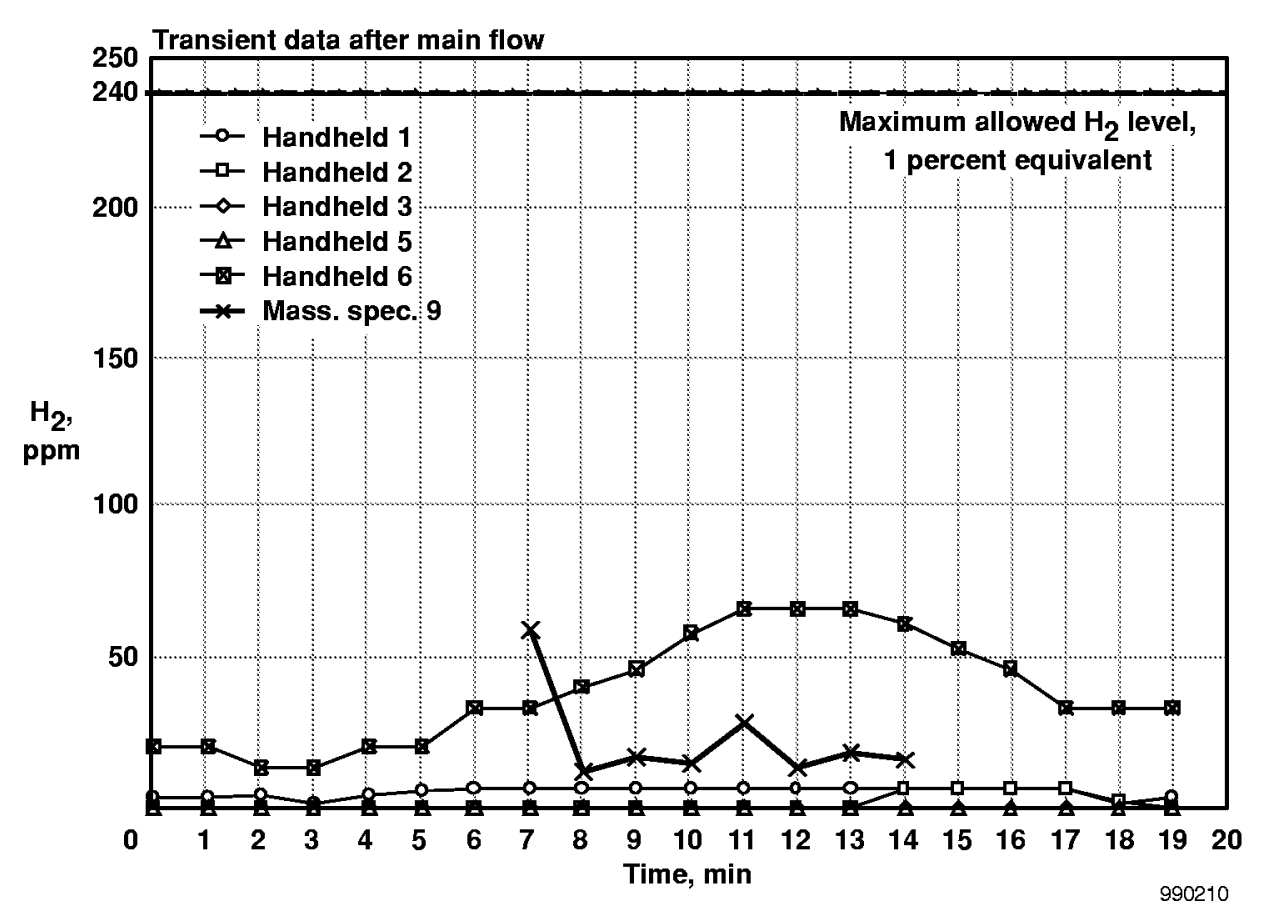

(a) After main flow.

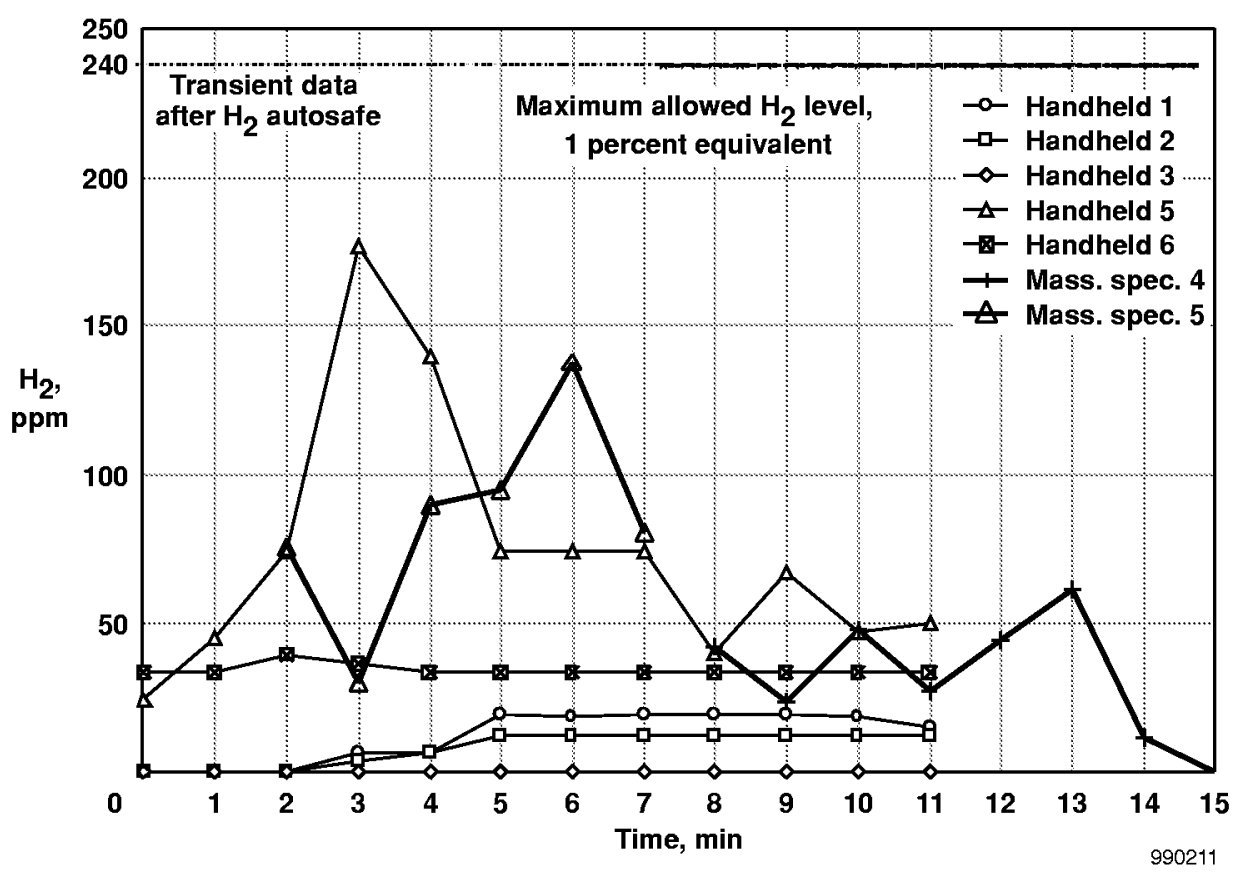

(b) After hydrogen autosafe.

Figure 8. Three-percent gaseous hydrogen blowdown data 

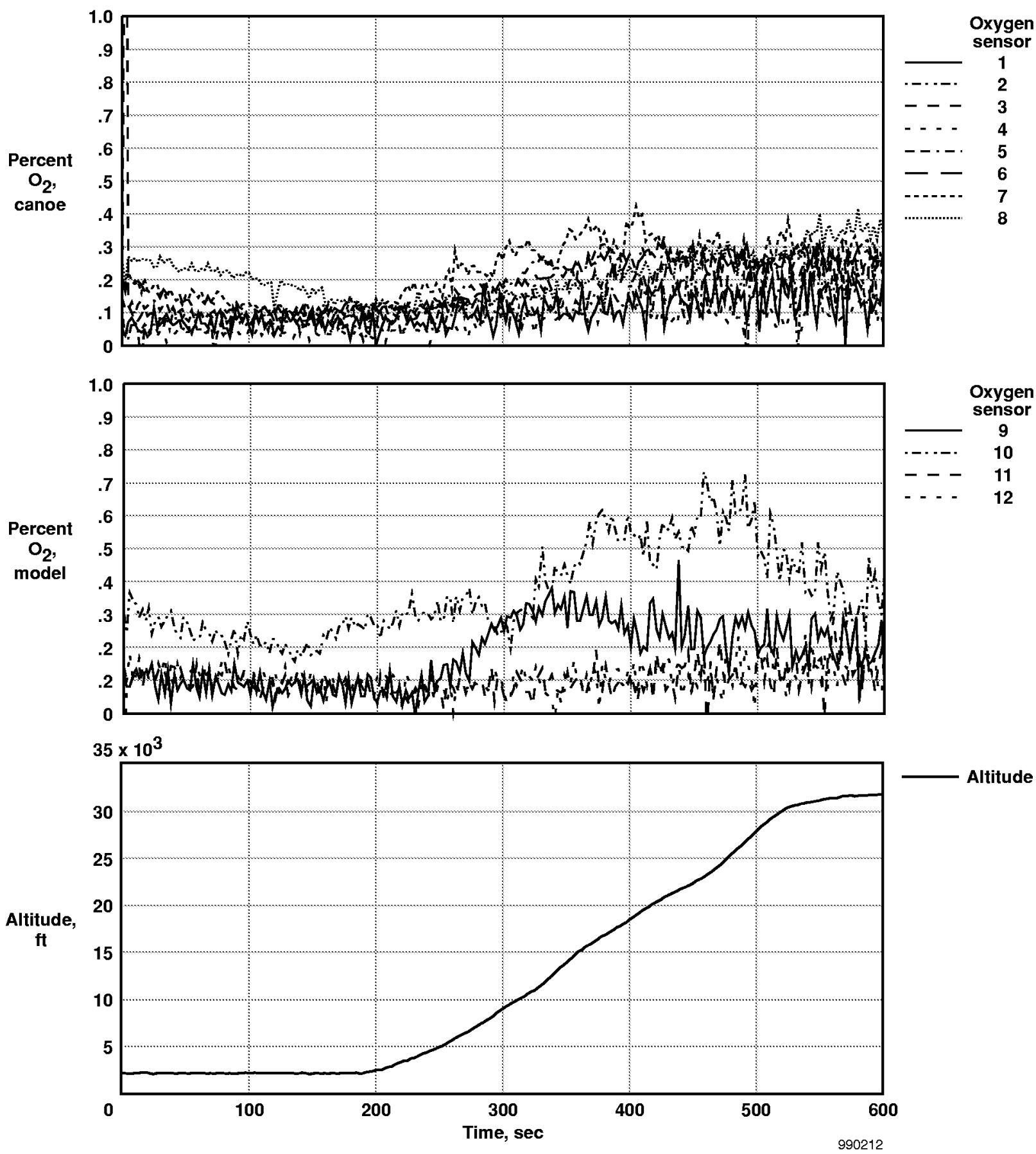

Altitude

Figure 9. Purge effectiveness with altitude change. 

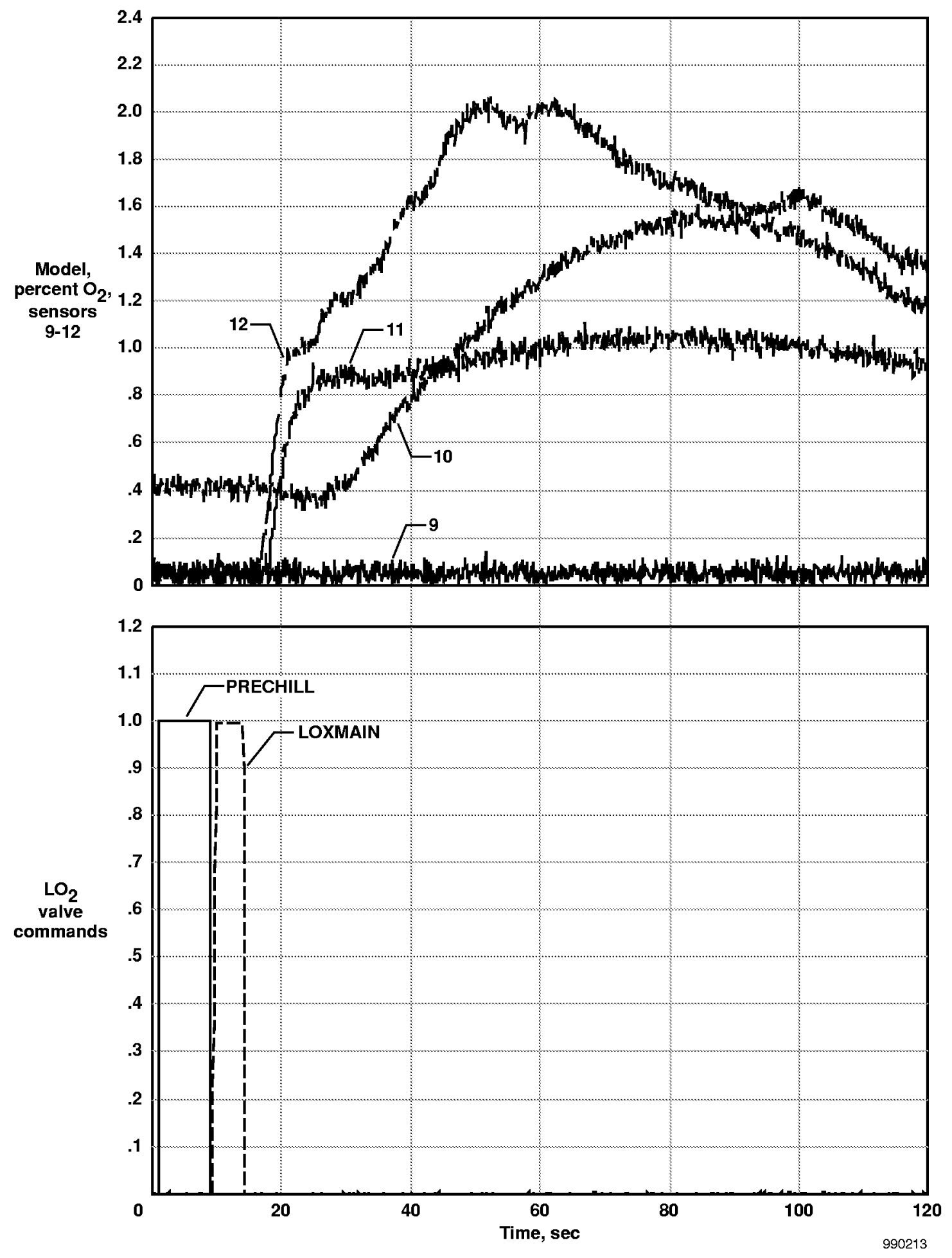

(a) Ground run 63 first main flow.

Figure 10. Oxygen sensor response. 

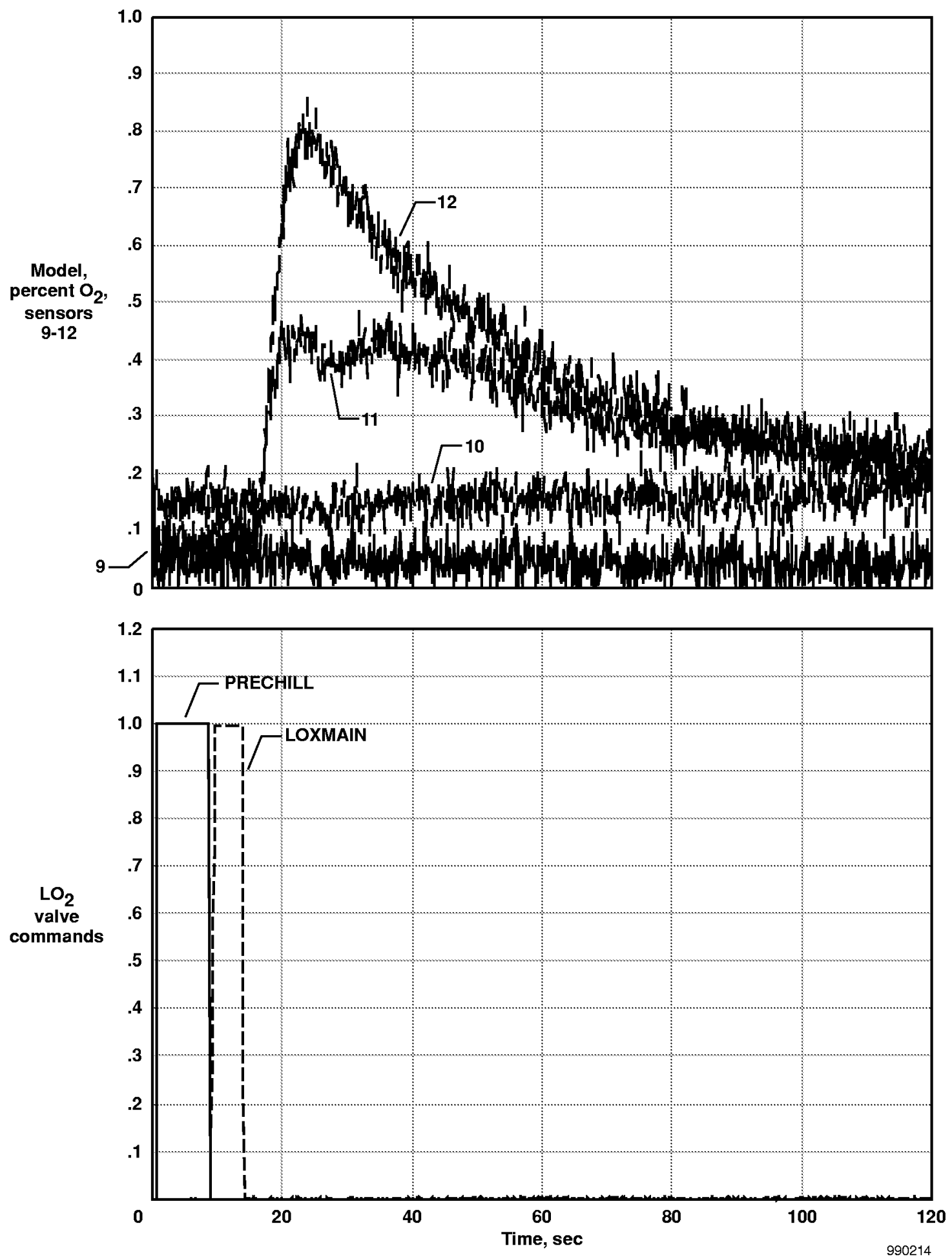

(b) Ground run 63 second main flow.

Figure 10. Continued. 

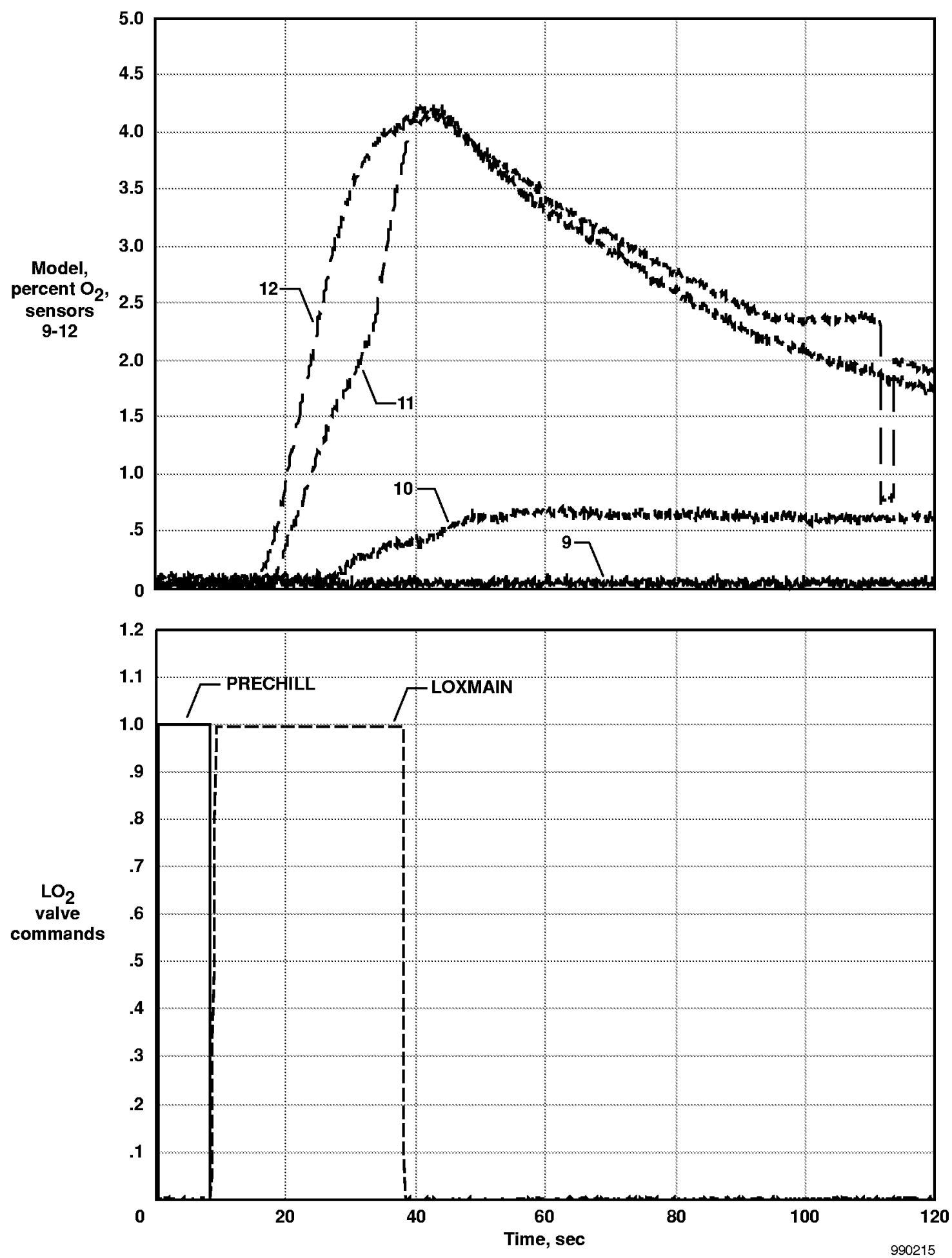

(c) Ground run 63 autosafe blowdown.

Figure 10. Continued. 

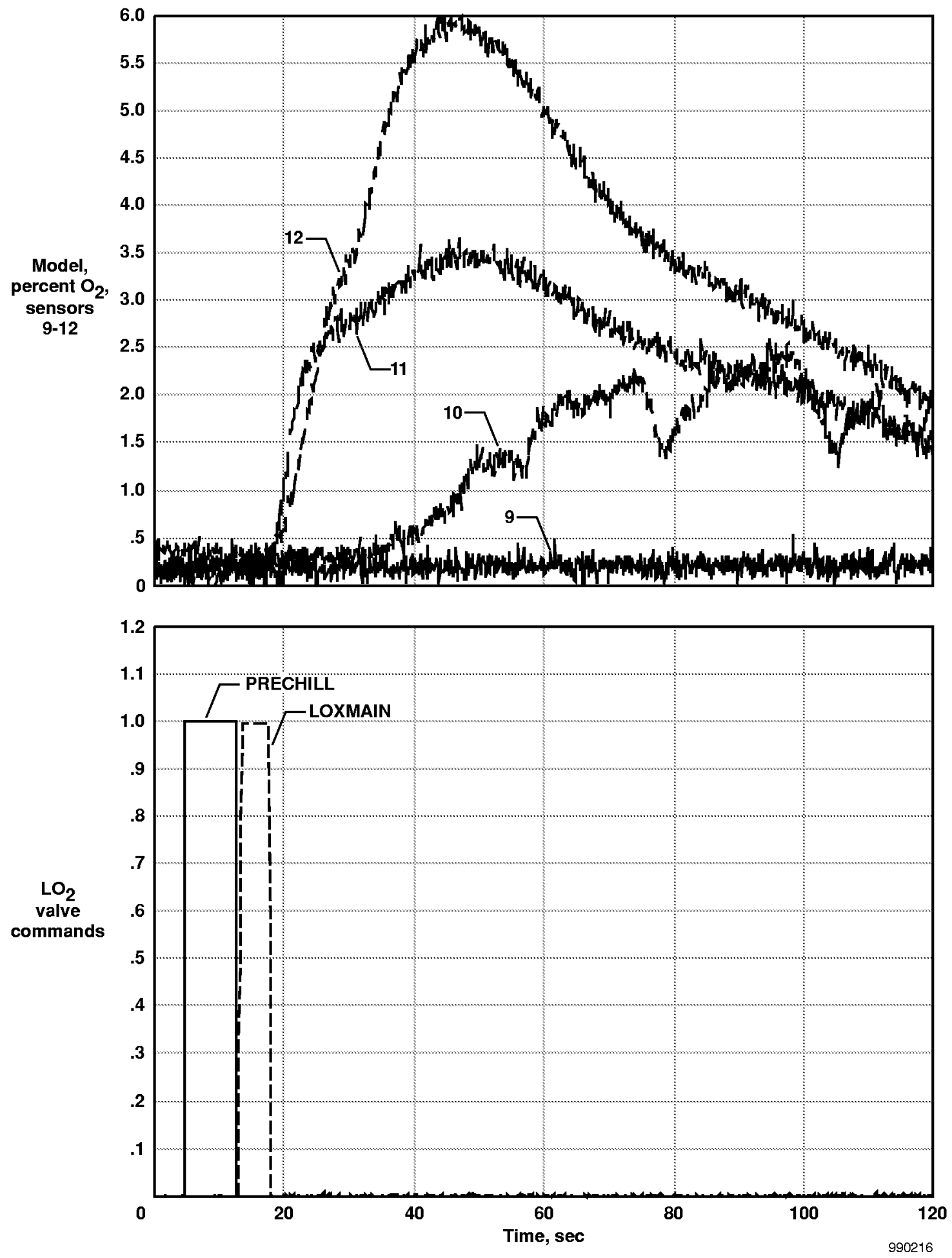

(d) Flight 51 main flow.

Figure 10. Continued. 

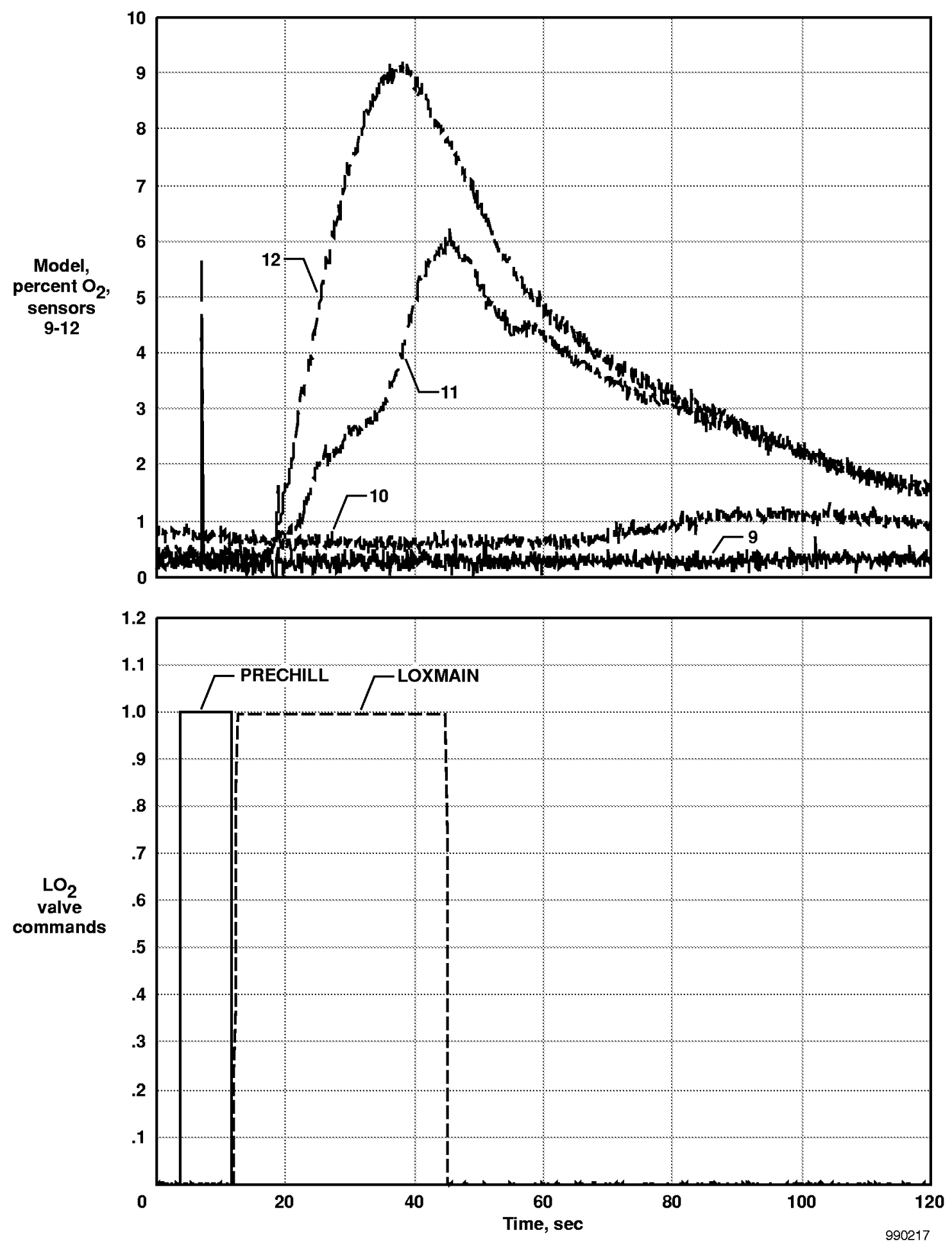

(e) Flight 51 autosafe blowdown.

Figure 10. Concluded. 


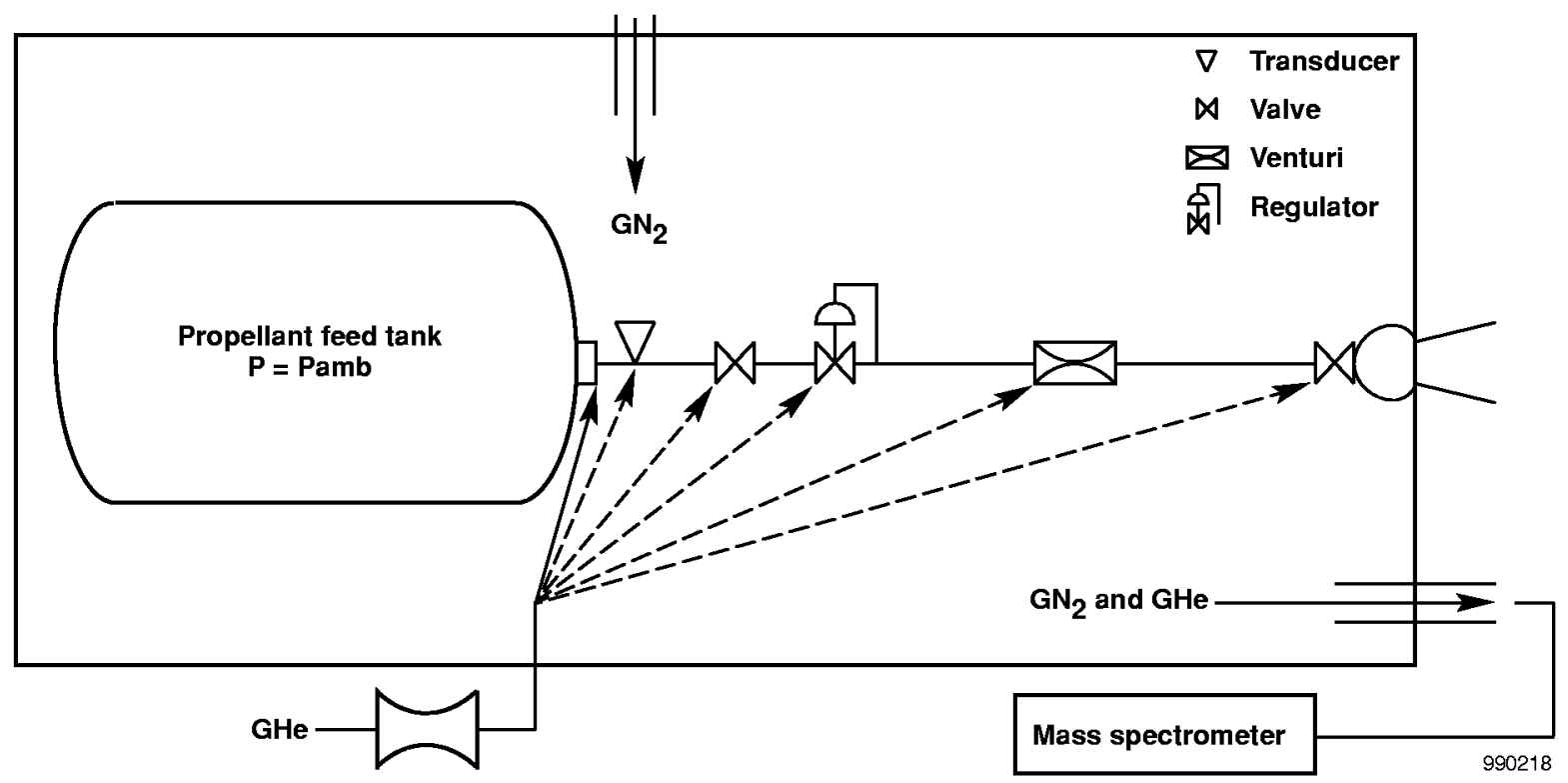

Figure 11(a). Gaseous helium characterization insertion point examples.

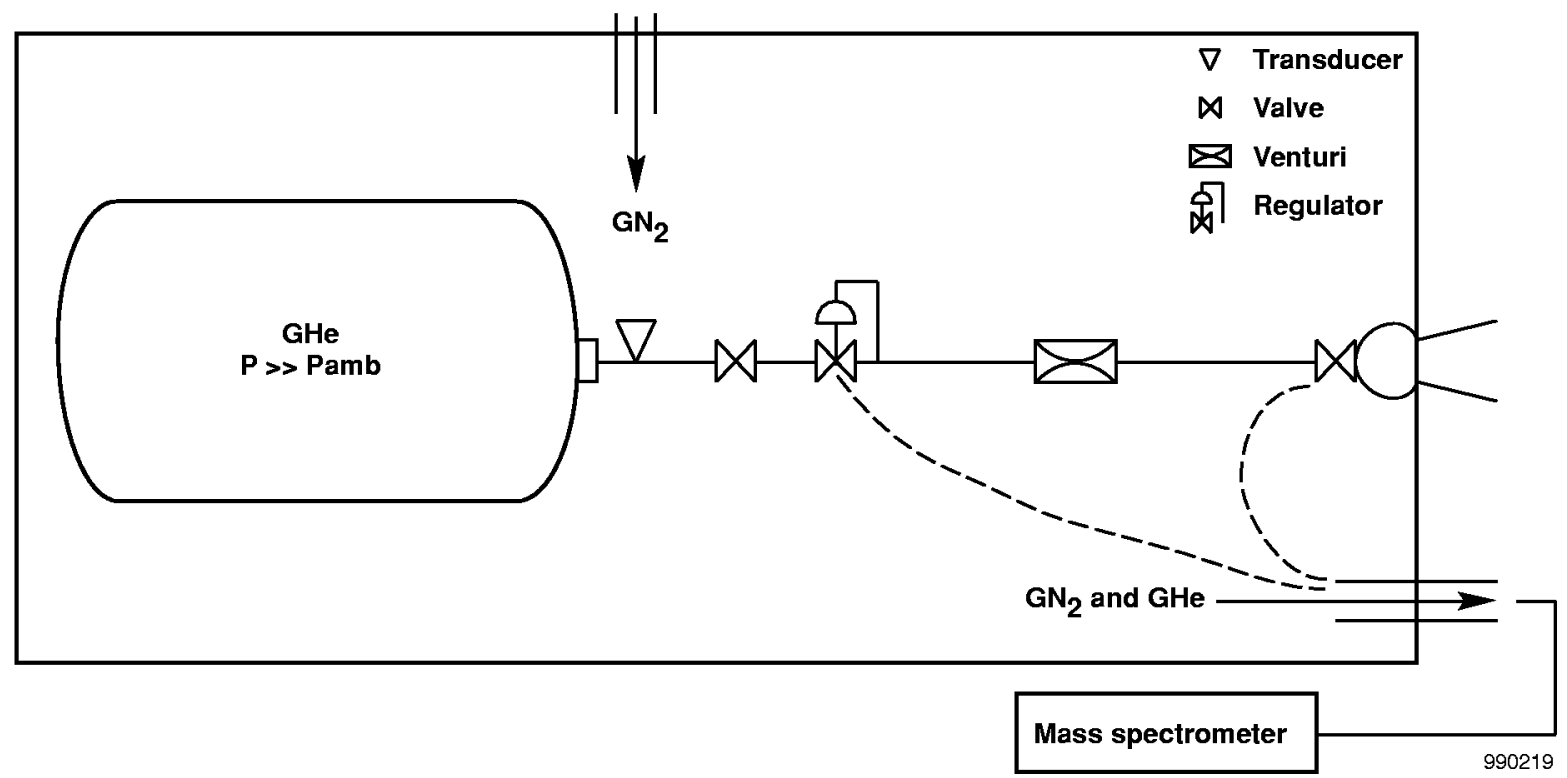

Figure 11(b). Gaseous helium back-pressure testing. 


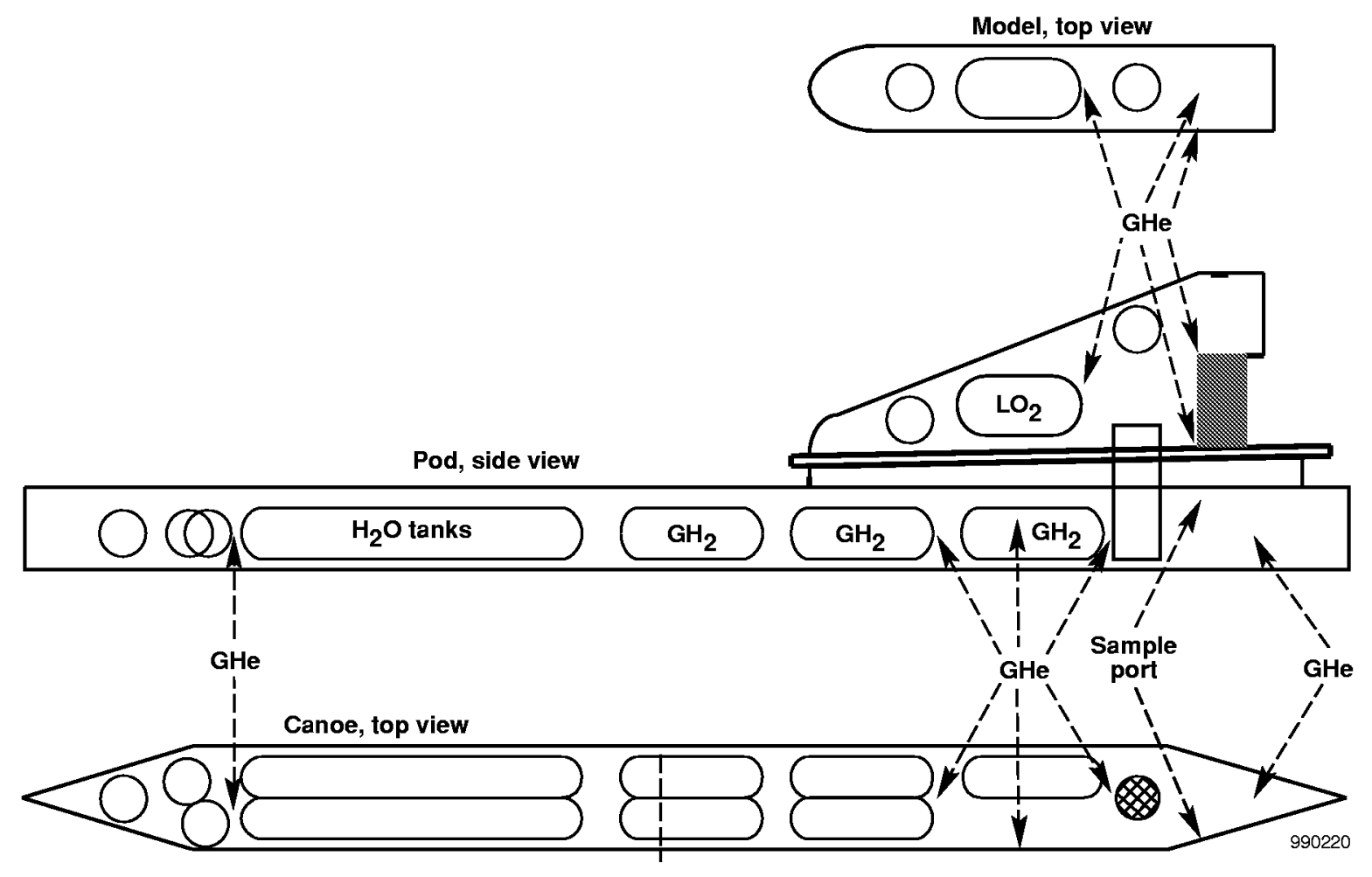

Figure 12. Gaseous helium insertion and mass spectrometer sample locations. 


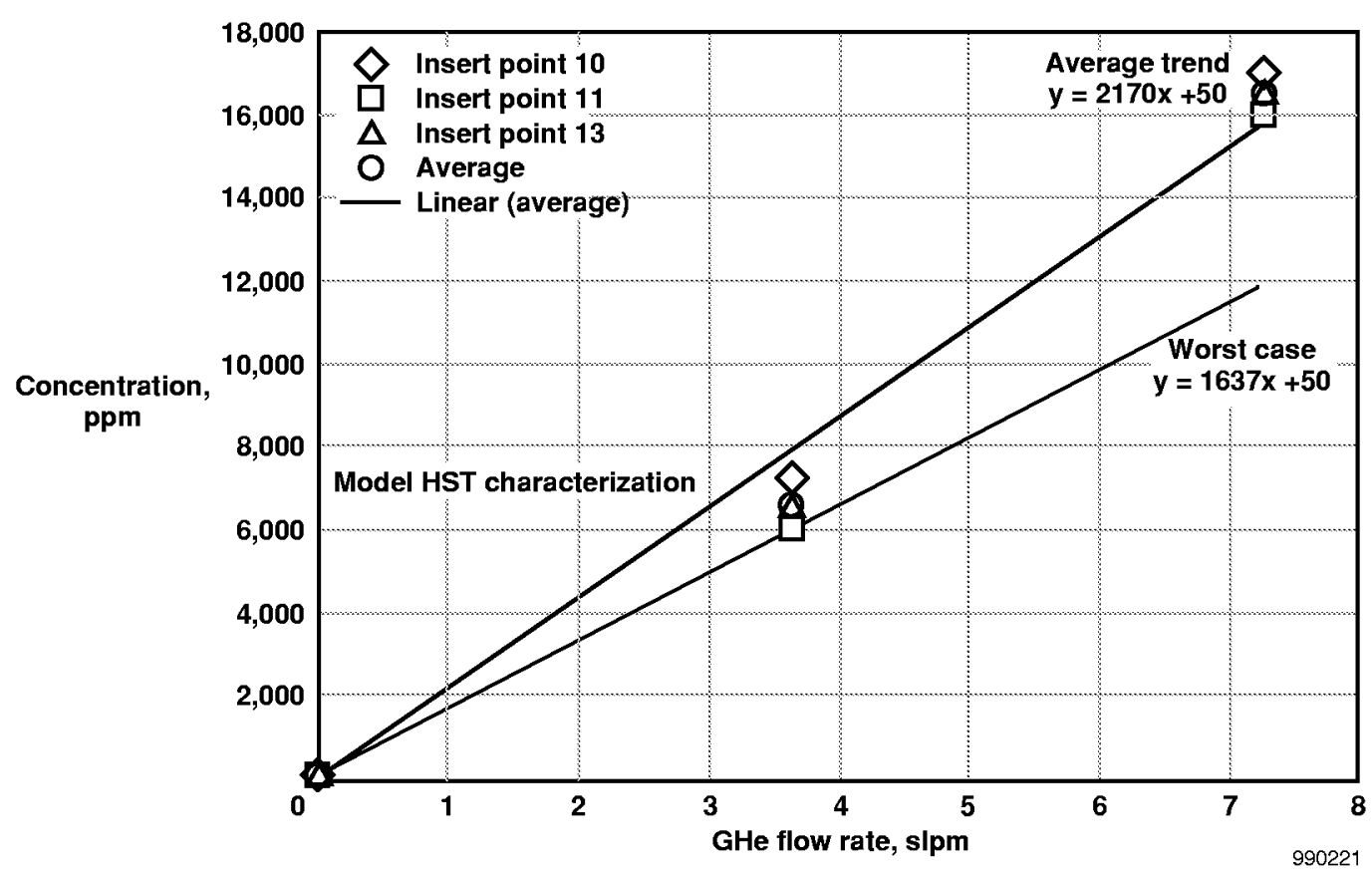

Figure 13(a). Gaseous helium insertion response.

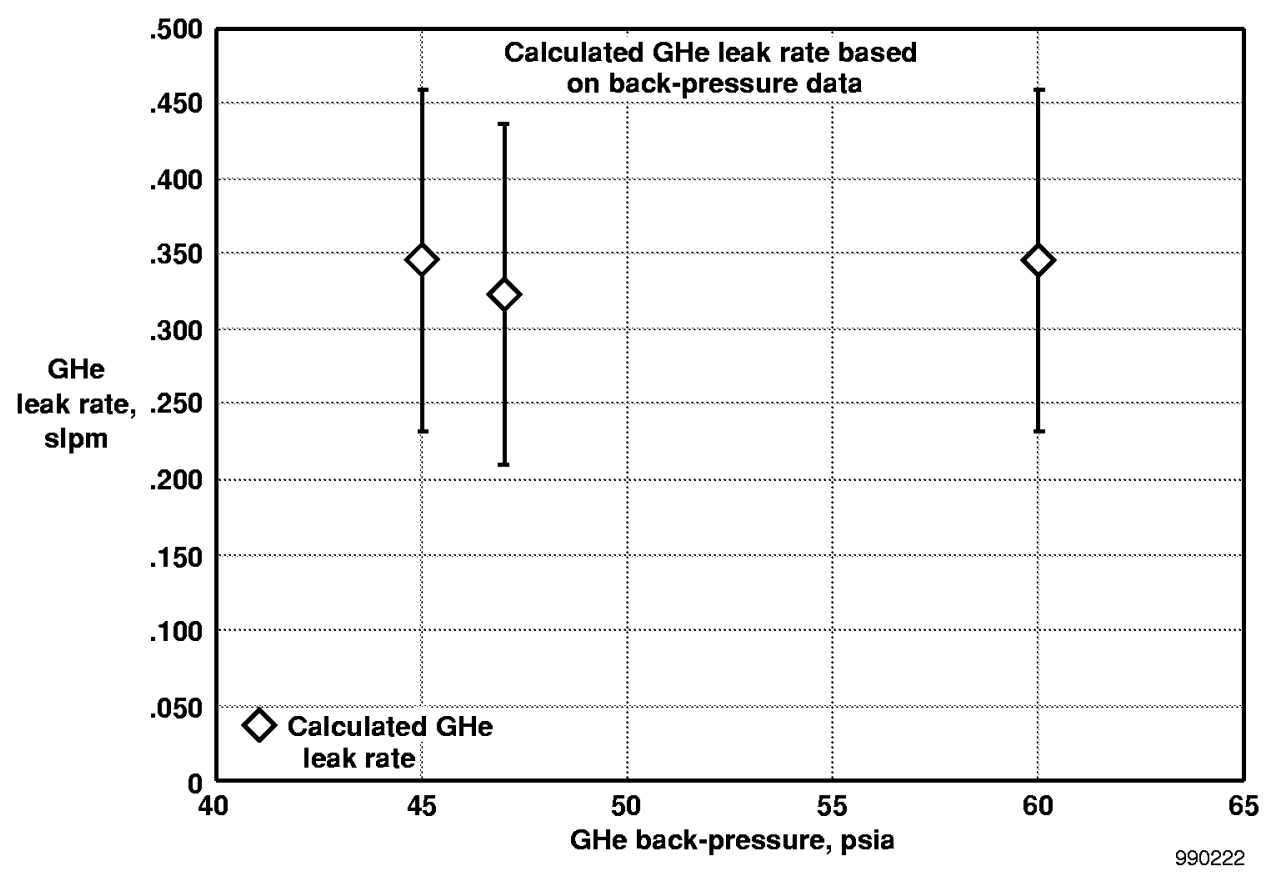

Figure 13(b). Gaseous helium leak rate due to back-pressure. 


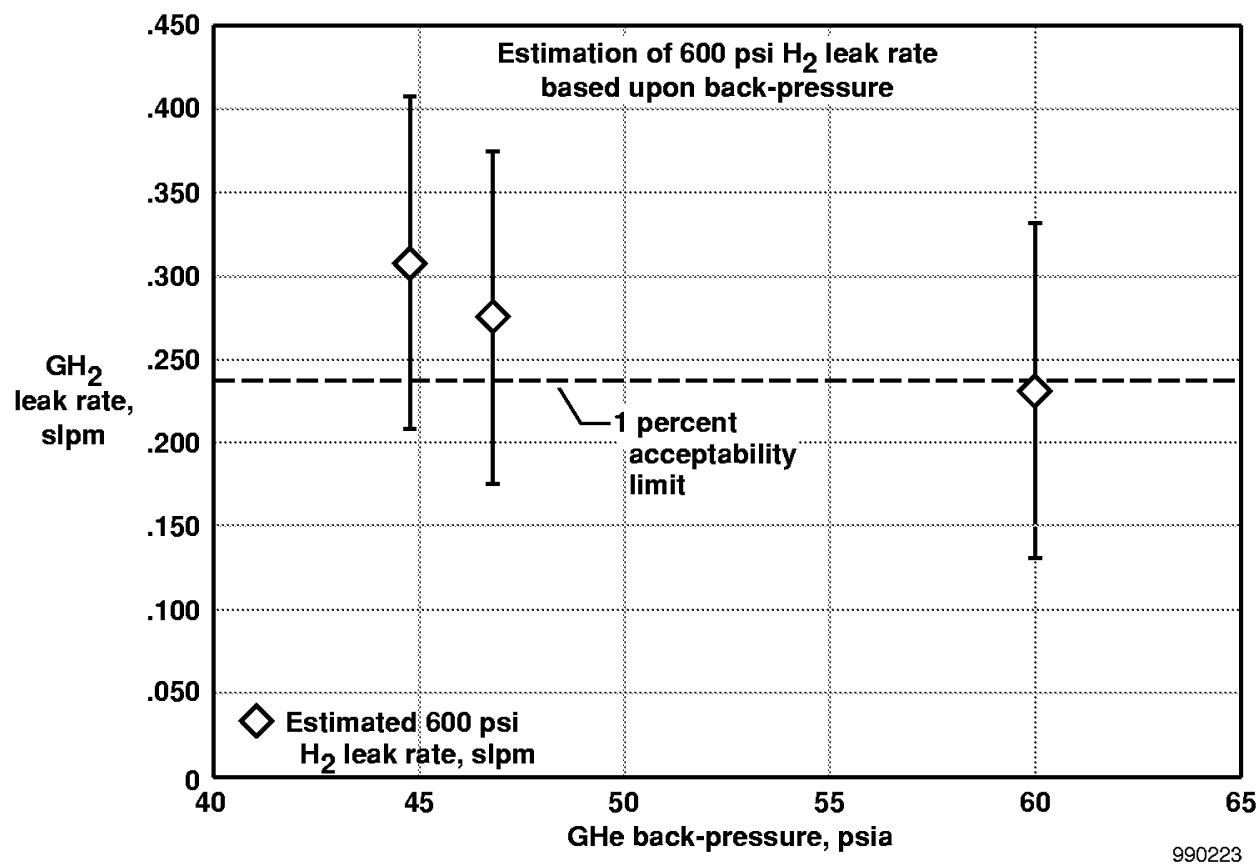

Figure 13(c). Estimated 600 psi gaseous hydrogen leak rate.

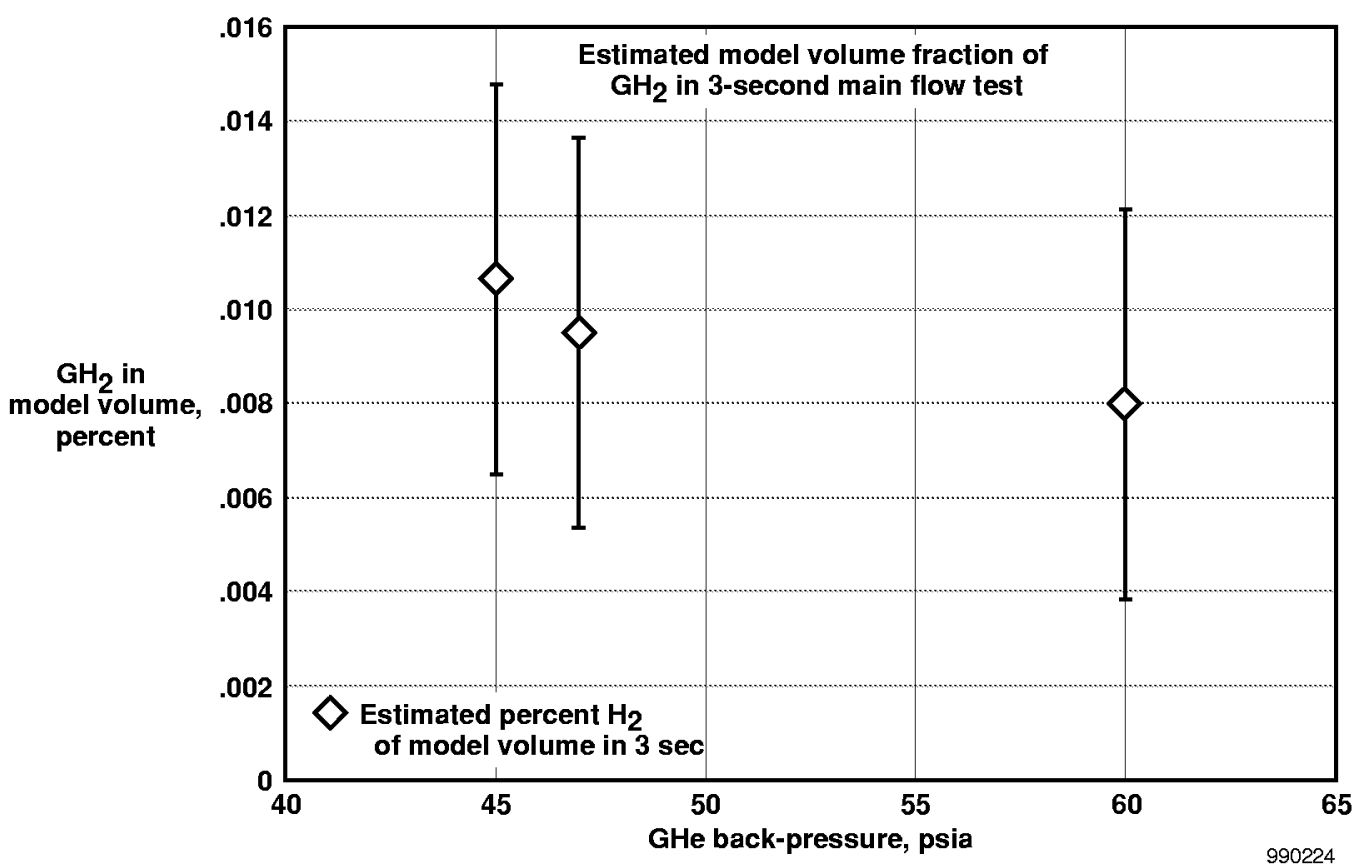

Figure 13(d). Estimated gaseous hydrogen concentration post-test. 

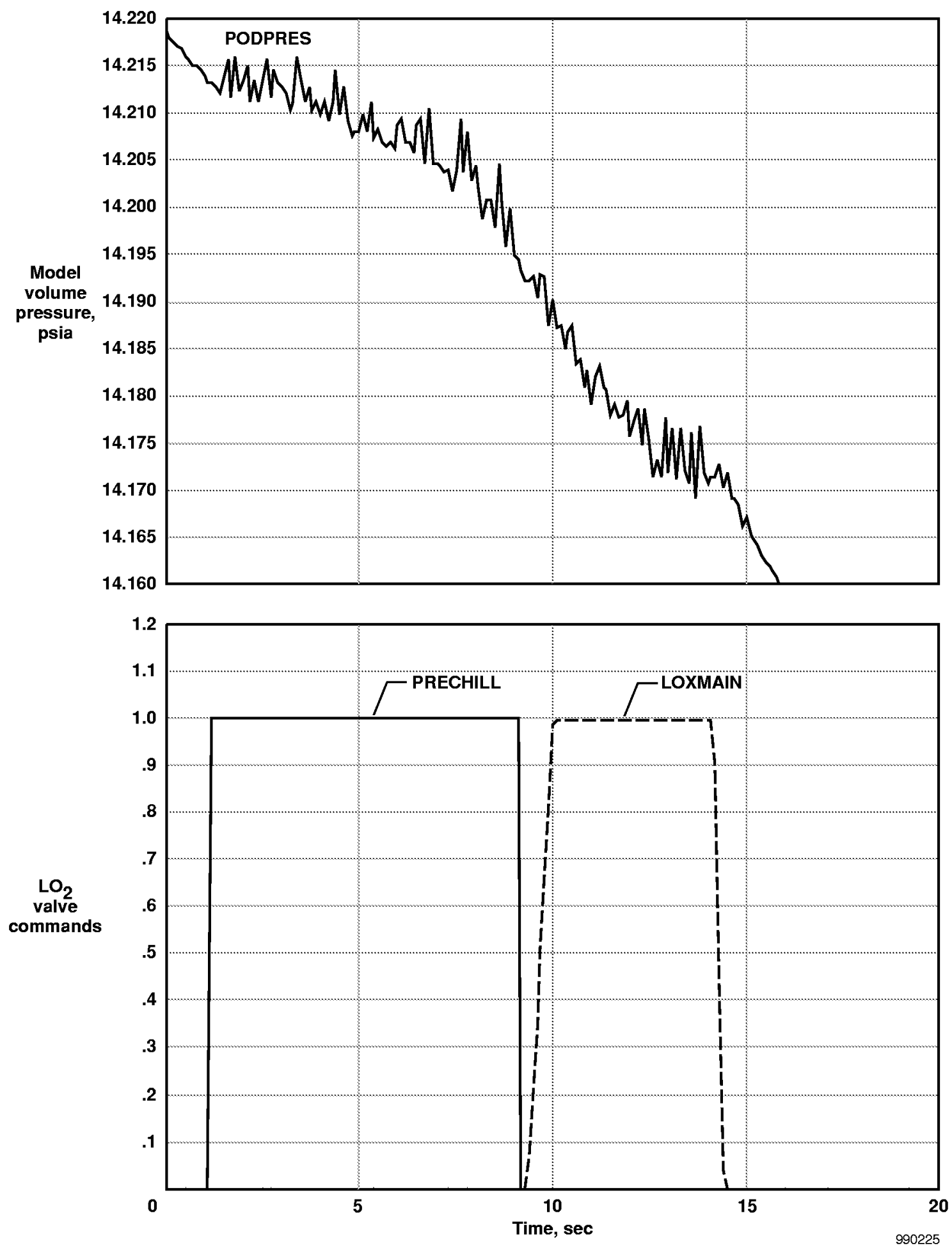

Figure 14(a). Model pressure sensor excitation during prechill and main flow. 

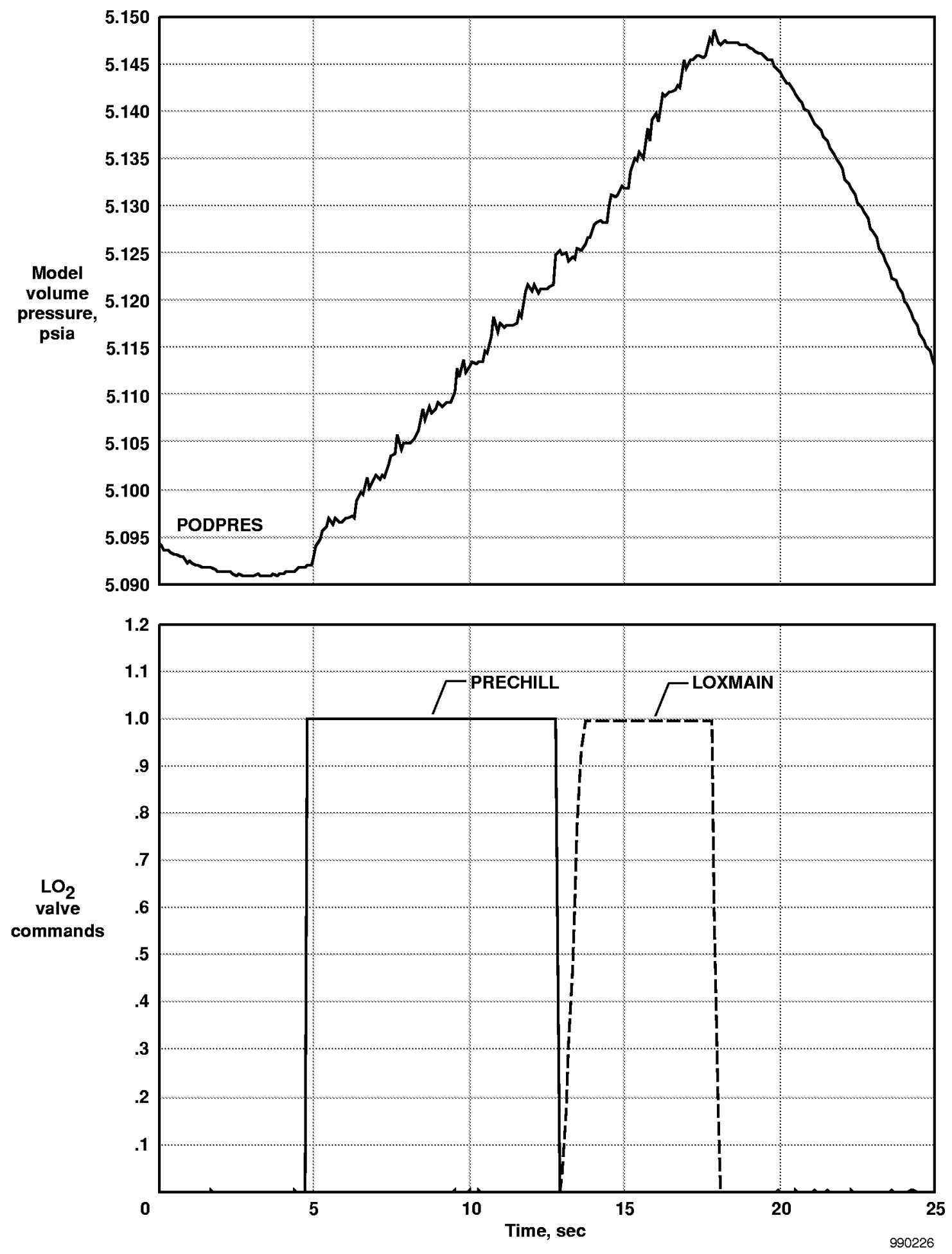

Figure 14(b). Model pressure sensor excitation during prechill and main flow in flight. 
Public reporting burden for this collection of information is estimated to average 1 hour per response, including the time for reviewing instructions, searching existing data sources, gathering and maintaining the data needed, and completing and reviewing the collection of information. Send comments regarding this burden estimate or any other aspect of this collection of information, including suggestions for reducing this burden, to Washington Headquarters Services, Directorate for Information Operations and Reports, 1215 Jefferson Davis Highway, Suite 1204, Arlington, VA 22202-4302, and to the Office of Management and Budget, Paperwork Reduction Project (0704-0188), Washington, DC 20503.

1. AGENCY USE ONLY (Leave blank)

2. REPORT DATE

3. REPORT TYPE AND DATES COVERED

November 1999 Technical Memorandum

4. TITLE AND SUBTITLE

Propellant Feed System Leak Detection-Lessons Learned From the

Linear Aerospike SR-71 Experiment (LASRE)

6. AUTHOR(S)

WU $2423302002300 \mathrm{~T} 15$

Neal Hass, Masashi Mizukami, Bradford A. Neal, Clinton St. John,

Robert J. Beil, and Timothy P. Griffin

7. PERFORMING ORGANIZATION NAME(S) AND ADDRESS(ES)

NASA Dryden Flight Research Center

P.O. Box 273

Edwards, California 93523-0273

8. PERFORMING ORGANIZATION

REPORT NUMBER

H-2378

9. SPONSORING/MONITORING AGENCY NAME(S) AND ADDRESS(ES)

10. SPONSORING/MONITORING AGENCY REPORT NUMBER

National Aeronautics and Space Administration

Washington, DC 20546-0001

NASA/TM-1999-206590

11. SUPPLEMENTARY NOTES

Presented at the AIAA 9th International Space Planes and Hypersonic Systems Conference, Norfolk, Virginia, November 1-5, 1999.

12a. DISTRIBUTION/AVAILABILITY STATEMENT 12b. DISTRIBUTION CODE

Unclassified-Unlimited

Subject Category 20

13. ABSTRACT (Maximum 200 words)

This paper presents pertinent results and assessment of propellant feed system leak detection as applied to the Linear Aerospike SR-71 Experiment (LASRE) program flown at the NASA Dryden Flight Research Center, Edwards, California. The LASRE was a flight test of an aerospike rocket engine using liquid oxygen and high-pressure gaseous hydrogen as propellants. The flight safety of the crew and the experiment demanded proven technologies and techniques that could detect leaks and assess the integrity of hazardous propellant feed systems. Point source detection and systematic detection were used. Point source detection was adequate for catching gross leakage from components of the propellant feed systems, but insufficient for clearing LASRE to levels of acceptability. Systematic detection, which used high-resolution instrumentation to evaluate the health of the system within a closed volume, provided a better means for assessing leak hazards. Oxygen sensors detected a leak rate of approximately 0.04 cubic inches per second of liquid oxygen. Pressure sensor data revealed speculated cryogenic boiloff through the fittings of the oxygen system, but location of the source(s) was indeterminable. Ultimately, LASRE was canceled because leak detection techniques were unable to verify that oxygen levels could be maintained below flammability limits.

\section{SUBJECT TERMS}

15. NUMBER OF PAGES

Fire safety, Hypersonic vehicles, Leak assessment, Leak detection, Rocket engines

38

7. SECURITY CLASSIFICATION OF REPORT

Unclassified

18. SECURITY CLASSIFICATION OF THIS PAGE

Unclassified

19. SECURITY CLASSIFICATION OF ABSTRACT

Unclassified

16. PRICE CODE

A03

NSN 7540-01-280-5500

20. LIMITATION OF ABSTRACT

Unlimited 